\title{
Türkçe Ders Kitaplarında Yer Alan Etkinliklerin Düşünme Becerileri Açısından
}

\author{
İncelenmesi \\ Emel-BAYRAK ÖZMUTLU*, Pınar-KANIK UYSAL **
}

• Geliş Tarihi: 30.05.2020 • Kabul Tarihi: 19.01.2021 • Çevrimiçi Yayın Tarihi: 08.04.2021

$\ddot{\mathbf{O} z}$

$\mathrm{Bu}$ araştırmada Türkçe ders kitaplarında yer alan etkinliklerin geliştirmeyi amaçladığı düşünme becerileri açısından nasıl bir dağılım gösterdiği ve bu düşünme becerilerinin incelenen etkinliklerde hangi yönleriyle ele alındığını incelemek amaçlanmaktadır. Araştırmada nitel araştırma yöntemlerinden biri olan doküman incelemesi yöntemi benimsenmiştir. Araştırmanın çalışma kapsamını 2018 yılında güncellenen Türkçe dersi öğretim programları sonrasında kullanılan ve Eğitim Bilişim Ağı (EBA) platformundan erişime açık olup elektronik olarak ulaşılabilen 8 adet Türkçe ders kitabında yer alan toplam 3.452 etkinlik oluşturmaktadır. Araştırmanın veri analizi sürecinde tekrarlı okuma, kodlama ve sürekli karşılaştırma yöntemi kullanılmıştır. Araştırma bulguları Türkçe ders kitaplarında yer alan etkinliklerin 21 farklı düşünme becerisini geliştirmeyi amaçladığını göstermektedir. Türkçe ders kitaplarında en fazla geliştirilmesi amaçlanan düşünme becerisi hatırlamadır. Çözümleme, sorgulama, karşılaştırma, tartışma, yaratıcı yazma, problem çözme ve değerlendirme düşünme becerilerinin düşük oranlara sahip olduğu görülmektedir.

Anahtar sözcükler: Dil becerileri, düşünme becerileri, üst düzey düşünme becerisi, Türkçe ders kitapları

\section{Atıf:}

Bayrak Özmutlu, E. \&. Kanık Uysal, P. (2021). Türkçe ders kitaplarında yer alan etkinliklerin düşünme becerileri açısından incelenmesi. Pamukkale Üniversitesi Eğitim Fakültesi Dergisi, 52, 518-543.doi: 10.9779/pauefd.745469.

\footnotetext{
*Doktor Öğretim Üyesi, Ordu Üniversitesi Eğitim Fakültesi, emelozmutlu@odu.edu.tr

** Doktor Öğretim Üyesi, Ordu Üniversitesi Eğitim Fakültesi, pinarkanikuysal@odu.edu.tr
} 


\section{Giriş}

Bilgi çağı olarak adlandırılan yirmi birinci yüzyılda bilgili olmak tek başına yeterli değildir. Yaşamın gittikçe karmaşıklaşması bilginin beceriye dönüştürülmesini zorunlu bir hale getirmiş ve becerilerinde gelişim sağlamış bireylere duyulan ihtiyacı artırmıştır (Mutluer 2013). Söz konusu beceriler özellikle eleştirel ve yaratıcı düşünme, etkili iletişim kurma, problemlere çözüm önerileri getirebilme, araştırma yapma, doğru kararlar verme, bilgi teknolojilerini kullanabilme ve girişkenlik olarak sıralanabilir (Durukan ve Demir, 2017). Bu becerilere sahip olan bir birey gündelik hayat problemlerine karşı doğru stratejiler kullanarak yaratıcı çözümler üretebilmekte ve bunları genelleyerek paylaşabilmektedir (Güneş, 2012). Üst düzey düşünme becerileri olarak adlandırılan bu beceriler öğrencilerin hayatlarının farklı aşamalarında yüzleştiği koşullar içinde ona rehberlik eder ve öğrenme sürecinde önemli bir rol üstlenir.

Toplumsal yaşamın bireyden üst düzey düşünme becerilerini kullanması ve bu becerileri geliştirip gelecekte ihtiyaç duyulacak formlara dönüştürme beklentisi (Söylemez, 2018) eğitim politikalarında alınan kararları şekillendirmektedir. Çünkü eğitim, bireyin ve toplumun beklentileri doğrultusunda şekillenen bir süreçtir. Bu etkinin en ciddi yansımasını 2005 y1lı itibariyle yürürlüğe giren öğretim programlarında görmek mümkündür. Üst düzey düşünme becerilerinin öğretim programlarının içsel bir parçası olarak, disiplinin olanakları çerçevesinde geliştirilmesi anlayışı bu yıldan itibaren uygulanan öğretim programlarının tamamında görülmektedir. Benimsenen anlayış öğrencinin düşünme becerisini geliştirme konusunda aracı bir rol üstlenen içerikle meşgul olmasını, içerik bilgisini anlamlı bir biçimde kullanmasını amaçlar (Fogarty ve McTighe, 1993). Öğretim programlarının yanında ülkemizde 21.yüzyıl becerileri ve Türkiye Yeterlilik Çerçevesi kapsamında yürütülen akademik ve politik çalışmaları da bu kapsamda değerlendirmek mümkündür.

Benimsenen öğretme öğrenme yaklaşımında yaşanan anlayış değişimi ile birlikte ders kitapları öğrenme sürecinde öğrenciyi düşünmeye sevk eden, sorgulayıcı bir yaklaşım kazanmasına ve farklı yaklaşımlarla değerlendirmelerde bulunmasına rehberlik eden bir öğretim aracı olarak karşımıza çıkmaktadır (Ocak ve Dai, 2010). Bu açıdan Türkçe dersi kitaplarında, öğretim programında benimsenen öğrenme yaklaşımı ile uyumlu olarak öğrencilerin ön öğrenmelerini ortaya çıkaran, gelecek öğrenmelere hazırlayan, gündelik yaşamları ile bağ kurmalarına ve dil becerilerini geliştirmelerini sağlayan metin ve etkinliklerin yer alması bir gerekliliktir. Bunun yanında ders kitaplarında Türkçe dersi öğretim programında yer alan temel becerileri geliştirmeyi amaçlayan etkinlikler yer 
E, Bayrak Özmutlu ve P, Kanık Uysal/ Pamukkale Üniversitesi Eğitim Fakültesi Dergisi, 52, 518-543, 2021 almalıdır (Erdoğan, 2014). Öğrencilerin küreselleşen dünyanın yarattığı koşullara uyum sağlayan karşılaştığı problemleri çözebilen bireyler olmanın gerektirdiği donanımlara sahip olmalarını sağlamak ders kitaplarının amaçları arasındadır (Ekinci, Çelikpazu ve Aktaş 2011).

Ders kitapları öğretim programları temelinde hazırlanan bir kaynak olarak öğretme öğrenme sürecinin en temel materyalidir (Büyükalan ve Yıldırım, 2019). Aynı zamanda kolay erişilebilir ve işlevsel bir materyali olarak kabul edilmektedir (Karadağ ve Tekercioğlu, 2019). Okullarda yürütülen öğretme öğrenme süreci uygulamalarında öğrenci ve öğretmenlere rehberlik etmektedir. Türkçe öğretiminde öğretmenler tarafından ders kitaplarının öncelikli olarak kullanıldığı bilinmektedir (Özbay, 2003). Türkçe dersinde öğrencilerin temel dil becerilerinin geliştirilmesinde ders kitapları ciddi bir role sahiptir. Bunun nedeni Türkçe derslerinde dil becerilerinin çoğunlukla ders kitaplarında yer verilen metinler ve bu metinler temelinde hazırlanmış olan etkinlikler aracılığıyla öğrencilere kazandırılmasıdır (Erdoğan, 2014).

Yukarıda işaret edildiği üzere ders kitapları öğretme öğrenme sürecinin niteliği açısından oldukça önemlidir. Eğitim bilimleri alanında bu açıdan Türkçe ders kitapları üzerinde yapılmış olan yakın dönem araştırmaları incelendiğinde ders kitaplarını öğretmen görüşleri (Arslan ve Engin, 2019; Süğümlü, Mutlu ve Çinpolat, 2019); PISA okuma becerileri yeterlik düzeyleri (Benzer, 2019); metinler (Çalışkan, 2016); dil becerileri (Çarkıt, 2019); tema değerlendirme ve metin altı soruları (Çeçen ve Kurnaz, 2015; Eroğlu ve Kuzu, 2014; Sarar-Kuzu, 2013; Savaşkan, 2016); etkinlikler (Çevik ve Güneş, 2017; Karadağ, 2019; Tosunoğlu ve Demir, 2014; Ulum ve Taşkaya, 2019); eleştirel düşünme becerilerini karşılama düzeyi (Demir ve Baş, 2019); disiplinler arası yaklaşım (Demir, 2018); okuma kazanımları (Deniz, Tarakçı ve Karagöl, 2019); dinleme/izleme kazanımları (Dolunay ve Savaş, 2016; Özkanal ve Bayrak, 2016); 21. yüzyıl becerileri (Gültekin, 2019); yapılandırmacı yaklaşım (Küçükaydın ve İşcan, 2017); programdaki temel beceriler (Kurudayığlu ve Soysal, 2019; Temizkan, 2014); program kazanımları (Uçgun, 2018) temelinde inceleyen araştırmalar olduğu görülmektedir. Ancak alanyazında ders kitaplarını 1. sınıftan 8.sınıfa geniş bir anlayış içinde ele alan bir araştırmaya rastlanmamıştır. Türkçe ders kitaplarının öğretimin tüm kademelerinde programdaki anlayışa uygun bir anlayış içinde geliştirilmesi gerekliliği dikkate alındığında ders kitaplarının geniş bir sınıf düzeyi örneklemi temelinde incelenmesi önemlidir. Öte yandan bu araştırmada ders kitaplarında yer alan etkinliklerin hangi düşünme becerilerini geliştirmeyi amaçladığına yönelik bir 
E, Bayrak Özmutlu ve P, Kanık Uysal/ Pamukkale Üniversitesi Eğitim Fakültesi Dergisi, 52, 518-543 521 çözümlemenin yanında her bir düşünme becerisinin hangi kapsamda ele alındığının da incelendiğini ifade etmek gerekmektedir.

$\mathrm{Bu}$ çalışma ders kitaplarının düşünme becerilerini geliştirme konusundaki niteliğini ortaya koymayı amaçlamaktadır. Ders kitaplarının üst düzey düşünme becerilerini geliştirme konusundaki niteliğini değerlendirme yollarından biri de her bir etkinliğin geliştirmeyi amaçladığı düşünme becerileri temelinde incelemektir. $\mathrm{Bu}$ inceleme ve çözümleme aracılığıyla ders kitapları ile etkileşim içindeki öğrencilerin bu süreç sonrasında geliştireceği düşünme becerilerinin neler olduğunu görmek mümkün olabilecektir. Araştırmada düşünme becerilerinin hangi kapsamda ele alındığı temelinde yapılan çözümleme ile de düşünme becerilerinin olanaklarından hangi oranda doğru ve etkili bir yolla yararlanıldığı değerlendirilebilecektir. Bu doğrultuda araştırmada aşağıdaki soruların cevabı aranmıştır:

1.İlkokul ve ortaokul düzeyinde Türkçe ders kitaplarında yer alan etkinlikler geliştirmeyi amaçladığı düşünme becerileri temelinde nasıl bir dağılım göstermektedir?

2.İlkokul ve ortaokul düzeyinde Türkçe ders kitaplarında yer alan etkinliklerde geliştirilmesi amaçlanan düşünme becerilerinin hangi yönüne odaklanılmıştır?

\section{Yöntem}

$\mathrm{Bu}$ araştırmanın amaçları doğrultusunda, çalışma grubuna dâhil edilen ders kitaplarında yer alan etkinlikler üzerinde bir incelemenin yürütülmesi gerekmektedir. Araştırmada bu nedenle nitel araştırma yöntemlerinden biri olan doküman inceleme yöntemi benimsenmiştir. Scott ve Marshall'a (2015) göre, doküman incelemesi bireysel ya da resmî dokümanların araştırma materyali olarak kullanılmasıdır. Bu araştırmada 2018 yılında güncellenen Türkçe dersi öğretim programları sonrasında kullanılan ve Eğitim Bilişim Ağı (EBA) platformundan erişime açık olup elektronik olarak ulaşılabilen 8 adet Türkçe ders kitabı incelenmiş ve çözümlenmiştir. $\mathrm{Bu}$ açıdan araştırmada doküman incelemesi yönteminin kullanılması uygun görülmüştür.

\section{Çalışma Kapsamı}

Bu araştırmada ölçüt örneklem kullanılmıştır. Ölçüt örneklem amaçlı örneklem türlerinden biridir. Patton (2014), belli ölçütleri sağlayan tüm durumların seçimi olarak bu örnekleme türünü tanımlanmıştır. Araştırma örnekleminin seçiminde; ilkokul ve ortaokul Türkçe derslerine ait 2018-2019 eğitim öğretim y1lında uygulanmakta olan ve EBA Platformundan dijital olarak ulaşılabilen ders kitapları olması ölçütleri belirlenmiştir. Araştırmanın çalışma grubunu, 2018 yılında kullanılan ve EBA platformundan erişime açık olup elektronik olarak 

ulaşılabilen 8 Türkçe ders kitabı oluşturmaktadır. Araştırmanın çalışma gurubunu oluşturan kitaplara yönelik bilgiler Tablo 1'de görülmektedir.

Tablo 1. Araştırmada İncelenen Etkinliklerin Öğretim Kademeleri Temelinde Dă̆ılımı

\begin{tabular}{lcc}
\hline Kademe & İncelenen Etkinlik Sayısı & Yayınevi \\
\hline 1.sınıf & 168 & Millî Eğitim Yayınevi \\
2.sınıf & 337 & Koza Yayıncılık \\
3.sınıf & 386 & Millî Eğitim Yayınevi \\
4.sınıf & 508 & Millî Eğitim Yayınevi \\
5.sınıf & 595 & Anıttepe Yayıncılık \\
6.sınıf & 447 & Millî Eğitim Yayınevi \\
7.sınıf & 552 & Millî Eğitim Yayınevi \\
8.sınıf & 459 & Millî Eğitim Yayınevi \\
\hline Toplam & 3.452 & \\
\hline
\end{tabular}

\section{Verilerin Analizi}

Araştırmanın veri analizi sürecinde tekrarlı okuma, kodlama ve sürekli karşılaştırma yönteminin kullanıldığı ayrıntılı bir analiz süreci takip edilmiştir. Araştırmanın analiz sürecinde çalışma kapsamına dâhil edilen ilkokul ve ortaokul Türkçe ders kitapları Max QDA programına yüklenmiştir. Tekrarlı olarak okumaların sonucunda ders kitaplarında yer alan etkinliklerin hangi düşünme becerisi ya da becerilerini geliştirmeyi amaçladığına karar verilmiştir. Etkinlikleri hangi düşünme becerisini geliştirmeyi amaçladığına karar verilirken, etkinlik üzerinde meşgul olan öğrencinin bu süreçte hangi düşünme becerisinin gelişmesinin olası olduğu sorusu yönlendirilmiştir. Bu süreçte, Bayrak-Özmutlu (2020) tarafindan geliştirilen zihinsel beceri kod ve açıklamalarından yararlanılmıştır. Araştırma kapsamında Bayrak-Özmutlu'nun (2020) araştırmasından yararlanılan 12 düşünme becerisi Tablo 2'de görüldüğü gibidir. Araştırmada bu kod ve açıklamaların dışında kalan 9 beceri, araştırmacılar tarafından analiz kapsamında tanımlanmıştır. Araştırmacılar tarafından geliştirilmiş olan düşünme becerilerine ilişkin açıklamalar Tablo 3 'te görüldüğü gibidir. 
E, Bayrak Özmutlu ve P, Kanık Uysal/ Pamukkale Üniversitesi Eğitim Fakültesi Dergisi, 52, 518-543 523

Analiz sürecine tema sonu değerlendirme soruları analize dâhil edilmemiştir. Etkinlikler, geliştirmeyi amaçladığı düşünme becerileri temelinde sınıflandırılarak her bir düşünme becerisi için ayrı bir dosya oluşturulmuştur. Türkçe ders kitaplarında geliştirilmesi amaçlanan 21 düşünme becerisi için 21 farklı belge oluşturulmuştur. Bu süreçte düşünme becerileri temelinde sınıflanan etkinlikler, tekrarlı olarak okunmuş ve sınıflandırmadaki tutarlılık kontrol edilmiştir. Kodlar arasındaki tutarlılık kontrolünün ardından tabloda yer alan etkinlikler, sınıflar ve kademeler temelinde sınıflandırılmıştır. Düşünme becerilerinin sınıf ve kademelere göre gösterdiği dağılım, betimleyici istatistiklerden yararlanarak özetlenmiştir. Araştırmanın ikinci alt problemini cevaplandırmak için aynı düşünme becerisini geliştirmeyi amaçlayan her bir etkinliğe “.... etkinlik ifadesinde, ... düşünme becerisinin hangi yönüne odaklanılmıştır?” sorusu yönlendirilerek bu temelde kodlanmıştır. $\mathrm{Bu}$ kapsamda etkinlik temelinde düşünme becerisinin hangi yönlerine odaklanıldı̆̆ 1 hangi yönlerinin ise dışarıda bırakıldı̆̆ını görmek amaçlanmıştır. $\mathrm{Bu}$ aynı zamanda analiz sürecinde çıkartılan düşünme becerilerinin kapsamını görmeyi mümkün kılmıştır. Düşünme becerisinin ders kitabında kullanılan yönü temelinde etkinliklere verilen kodlara göre yapılan sınıflama kümeleri üzerinde, sürekli karşılaştırma yöntemi uygulanarak gerekli birleştirme ve ayırma işlemleri yapılmıştır. Tekrarlı okumaların ardından kategoriler değişmeyen bir duruma gelinceye kadar bu işlem sürdürülmüştür. Analiz işlemi sürecinde kullanılan ve çıkartılan düşünme becerilerine (kategorik yapılar) ilişkin açıklamalar aşağıda verilmiştir:

Tablo 2. Analiz Kapsamında Kullanılan Düşünme Becerileri ve Tanımları

Düşünme becerisi Tanım

Hatırlama Öğrencinin yönergeler doğrultusunda daha önce öğrenmiş olduğu bilgileri zihinsel olarak geri çağırması ve sözlü ya da yazılı olarak ifade etmesi

Çıkarımda Bulunma Öğrencinin okuduğu, dinlediği/izlediği içerikle kişisel anlam oluşturma sürecine dâhil olması, bu sürecin içerdiği zihinsel işlemleri yerine getirmesi ve o içerikle ilintili art alan bilgisini birleştirmesi (Bkz. Keene ve Zimmermann, 1997).

Ayırt Etme

Öğrencinin okuduğu, dinlediği/izlediği dilsel uyaranlar arasından, istenilen unsuru/ özelliği fark etmesi (bulması, belirlemesi) ve bu 

unsura uygun tepkide bulunmas1

Tahmin Etme

Kural Uygulama

Değerlendirme

Anlam Temelli

Yapilandirma

Çözümleme

Problem Çözme

Sorgulama

Dönüştürme

Karşılaştırma
Öğrencinin okuduğu, dinlediği/izlediği dilsel uyaranlara dayalı olarak kestirimlerde bulunmas1

Öğrencinin dil becerileri alanına giren işlemsel bilgileri kuralına uygun olarak hayata geçirmesi

Öğrencinin okuduğu, dinlediği/izlediği dilsel uyaranların anlamını, önemini, niteliğini ve niceliğini birtakım ölçütler temelinde ele alması ve vardığı yargıyı yazılı ya da sözlü olarak ifade etmesi

Öğrencinin verilen yönergeye uygun olarak yapılandırdığı anlamı yazılı ya da sözlü olarak ifade etmesi

Öğrencinin okuduğu, dinlediği/izlediği dilsel uyaranları ögelerine/temel parçalarına basamaklarına ayırması ve bu ögeler/temel parçalar arasındaki ilişkileri kavraması

Öğrencinin okuduğu, dinlediği/izlediği dilsel uyaranlarda ifade edilen problemlere yönelik çözüm/çözümler geliştirmesi

Öğrencinin okuduğu, dinlediği/izlediği dilsel uyaranların anlamına, geçerliğine ve güvenirliğine ilişkin sorular oluşturması ve bu kapsamdaki konuşmalara katılması

Öğrencinin okuduğu, dinlediği/izlediği yazılı, görsel, söz ve harekete dayalı uyaranları yönergeye uygun olarak birbirine dönüştürmesi

Öğrencinin okuduğu, dinlediği/izlediği dilsel uyaranların biçim/ anlam açısından benzer ya da farklı yanlarını ortaya çıkarmak için incelemesi 
Tablo 3. Analiz Kapsamında Kullanılan Düşünme Becerileri ve Tanımları

\begin{tabular}{|c|c|}
\hline Düşünme Becerisi & Tanım \\
\hline Eşleştirme & $\begin{array}{l}\text { Öğrencinin okuduğu, dinlediği/izlediği uyaranlar arasında yönergede } \\
\text { ifade edilen özellikler açısından ortaklık ve benzerlikler temelinde } \\
\text { eşleştirmesi }\end{array}$ \\
\hline Görsel Okuma & $\begin{array}{l}\text { Öğrencinin yazılı metin harici afiş, fotoğraf, grafik, harita, işaret, } \\
\text { karikatür, resim, sembol, şekil, tablo vb. ögeleri anlamlandırması, } \\
\text { yorumlaması ve bunları yazılı ve/veya sözlü olarak ifade etmesi }\end{array}$ \\
\hline $\begin{array}{l}\text { Neden-Sonuç İlişkisi } \\
\text { Kurma }\end{array}$ & $\begin{array}{l}\text { Öğrencinin dinlediği/izlediği ve okuduklarında geçen eylemler } \\
\text { arasında neden ve sonuca dayalı ilişki kurması ya da bu ilişkiyi fark } \\
\text { etmesi ve bunları yazılı ya da sözlü olarak ifade etmesi }\end{array}$ \\
\hline Yaratıcı Yazma & $\begin{array}{l}\text { Öğrencinin duygu, düşünce, izlenim ve hayallerini kurgusal ya da } \\
\text { kurgusal olmayan yollarla bilgilendirme amacı gütmeden yazılı } \\
\text { olarak ifade etmesi }\end{array}$ \\
\hline Tasarlama & $\begin{array}{l}\text { Öğrencinin yönergeye uygun olarak belli bir amaca hizmet edecek } \\
\text { materyal ya da dilsel ürünü zihinde canlandırması, biçimlendirmesi } \\
\text { ve zihinsel yaratımlarını yazılı ya da sözlü olarak ifade etmesi }\end{array}$ \\
\hline Öz Değerlendirme & $\begin{array}{l}\text { Öğrencinin dil becerilerine dayalı olarak gösterdiği performans } 1 \\
\text { birtakım ölçütler temelinde ele alarak vardığı yargıyı yazılı ya da } \\
\text { sözlü olarak ifade etmesi }\end{array}$ \\
\hline Bilgi Kaynaklarına & Öğrencinin yönergede ifade edilen konuya ilişkin ikincil kaynaklara \\
\hline Ulaşma & $\begin{array}{l}\text { ulaşarak ulaştığı bilgileri yazılı, sözlü ya da görsel yollarla ifade } \\
\text { etmesi }\end{array}$ \\
\hline Yorumlama & $\begin{array}{l}\text { Öğrencinin okuduğu, dinlediği/izlediği özdeyiş, atasözü, deyim, } \\
\text { deyiş, söz öbeği, metafor, dize gibi dilsel unsurların anlamlarına } \\
\text { ilişskin açıklamalarda bulunması }\end{array}$ \\
\hline Tartışma & $\begin{array}{l}\text { Öğrencinin yönergelerde ifade edilen tartışmaya açık durum, koşul, } \\
\text { şart, problem, olasılıkların olası sebep ve sonuçları üzerinde fikir } \\
\text { üretmesi, fikirlerini yazılı ya da sözlü olarak ifade etmesi }\end{array}$ \\
\hline
\end{tabular}


Çözümleme işleminin tamamlanmasının ardından iki araştırmacı bir araya gelmiş ve kodlayıcılar arası uyum katsayısı hesaplanmıştır. Hesaplama sonrasında kodlayıcılar arası uyum katsayısı oranı \%97 olarak belirlenmiştir.

\section{Geçerlilik ve Güvenirlik Çalışmaları}

Nitel araştırma yönteminin benimsendiği bu araştırmada geçerlilik ve güvenirlik çalışmaları kapsamında aşağıdaki çalışmalar yürütülmüştür. Nitel araştırmalarda geçerlilik ve güvenirlik çalışmalarından biri olan inandırıcılık, toplanan verilerin doğruluğu ve inandırıcılı̆̆ anlamına gelmektedir (Güler, Halıcıoğlu ve Taşgın, 2014). Bu araştırmada 2018-2019 yılında Türkiye'de devlet okullarında okutulan ve EBA Genel Ağ sayfasından dijital olarak ulaşılabilen ders kitapları incelenmiştir. Araştırma kapsamında çözümlenen veriler, ders kitaplarında basılıp yayımladığı şekliyle alınmıştır. $\mathrm{Bu}$ açıdan araştırmada incelenen verilerin inandırıcılık gerekliliğini sağladığı söylenebilir. Nitel araştırmalarda inandırıcılığ sağlamanın bir diğer yolu çalışma grubunun özellikleri, sayısı, nasıl seçildiği, araştırma kapsamında kullanılan veri toplama araç ve analiz tekniklerine yönelik ayrıntılı bilgilere yer verilmesidir (Creswell ve Miller, 2000). Sözü edilen gereklilik kapsamında araştırmanın yöntem başlığı altında yukarıda sözü geçen bilgiler ayrıntılı biçimde açıklanmıştır. Nitel araştırmalarda güvenirlik gerekliliklerinden biri kodlayıcılar arası güvenirliktir. $\mathrm{Bu}$ gereklilik kapsamında çözümlemeler iki araştırmacı tarafından bağımsız olarak gerçekleştirilmiştir. Araştırmacılardan biri eğitim programları ve öğretim, diğeri Türkçe eğitimi alanında uzman öğretim üyesidir. Araştırmanın güvenirlik hesaplamasında Miles ve Huberman (2016) tarafindan önerilen “Güvenirlik = Görüş Birliği / (Görüş Birliği + Görüş Ayrılığı) x 100" güvenirlik formülünden faydalanılmıştır. Güvenirlik hesaplaması araştırmanın güvenirliğinin \%97 olduğunu göstermiştir. Verilerin çözümlenmesi sürecinde her bir araştırmacı, etkinliği neden bu düşünme becerisi ile kodladığına ilişkin notlar almıştır. Kodlayıcılar arası uyumun olmadığı etkinlikler çözümleme sürecinde alınan bu notlar ve alanyazın incelemelerine dayalı olarak geliştirilen açıklamalar temelinde birlikte değerlendirilmiştir. Kodlanan her bir etkinlik üzerinde uzlaşmaya varıncaya kadar değerlendirmeler sürdürülmüştür. Bunun yanında yöntem bölümünde kodların tanım ve açıklamalarına yer verilmesi ve bulgular bölümünde her koda ait doğrudan alıntıların paylaşılması yoluyla çalışmanın geçerliliği ve güvenilirliği artırılmaya çalışılmıştır. 


\section{Bulgular}

\section{Araştırmanın Birinci Alt Problemine İlişkin Bulgular}

Araştırmanın ilk probleminde "Türkçe ders kitaplarında yer alan etkinliklerin geliştirmeyi amaçladığı düşünme becerileri kademelere göre nasıl bir dağılım göstermektedir?" sorusunun cevabı aranmıştır. İfade edilen alt problemin cevabı Tablo 4 'te görülmektedir.

Tablo 4. Türkçe Ders Kitaplarında Yer Alan Etkinliklerin Geliştirmeyi Amaçladı̆̆g Düşünme Becerileri Temelinde Dă̆ılımı

\begin{tabular}{|c|c|c|c|c|c|c|c|c|c|c|}
\hline \multirow[t]{2}{*}{ Düşünme Becerileri } & \multicolumn{2}{|c|}{ 1.sinif } & \multicolumn{2}{|c|}{ 2.sinif } & \multicolumn{2}{|c|}{ 3.sinif } & \multicolumn{2}{|c|}{ 4.sinif } & \multicolumn{2}{|c|}{ Ortalama } \\
\hline & $\mathrm{f}$ & $\%$ & $\mathrm{f}$ & $\%$ & $\mathrm{f}$ & $\%$ & $\mathrm{f}$ & $\%$ & $\mathrm{f}$ & $\%$ \\
\hline Anlam Temelli & 2 & 1,19 & 10 & 2,97 & 2 & 0,52 & 2 & 0,39 & 16 & 1,14 \\
\hline \multicolumn{11}{|l|}{ Yapılandırma } \\
\hline Ayırt Etme & 7 & 4,17 & 19 & 5,64 & 9 & 2,33 & 12 & 2,36 & 47 & 3,36 \\
\hline Bilgi Kaynaklarına & 0 & 0,00 & 8 & 2,37 & 0 & 0,00 & 21 & 4,14 & 29 & 2,07 \\
\hline \multicolumn{11}{|l|}{ Ulaşma } \\
\hline Çıkarımda Bulunma & 10 & 5,95 & 31 & 9,20 & 35 & 9,06 & 50 & 9,86 & 126 & 9 \\
\hline Çözümleme & 0 & 0,00 & 1 & 0,30 & 4 & 1,04 & 2 & 0,39 & 7 & 0,5 \\
\hline Değerlendirme & 5 & 2,98 & 0 & 0,00 & 5 & 1,30 & 2 & 0,39 & 12 & 0,86 \\
\hline Dönüştürme & 0 & 0,00 & 0 & 0,00 & 1 & 0,26 & 4 & 0,79 & 5 & 0,36 \\
\hline Eşleştirme & 18 & 10,71 & 37 & 10,98 & 16 & 4.15 & 29 & 5,71 & 100 & 7,15 \\
\hline Görsel/Grafik/Tablo & 7 & 4,17 & 9 & 2,67 & 8 & 2,07 & 21 & 4,13 & 45 & 3,22 \\
\hline \multicolumn{11}{|l|}{ Okuma } \\
\hline Hatırlama & 87 & 51,79 & 158 & 46,88 & 238 & 61,66 & 241 & 47,44 & 724 & 51,75 \\
\hline Neden-Sonuç İlişkisi & 4 & 2,38 & 10 & 2,97 & 6 & 1,55 & 17 & 3,35 & 37 & 2,64 \\
\hline
\end{tabular}




\begin{tabular}{|c|c|c|c|c|c|c|c|c|c|c|}
\hline Karş1laştırma & 1 & 0,60 & 3 & 0,89 & 0 & 0,00 & 8 & 1,57 & 12 & 0,86 \\
\hline Kural Uygulama & 14 & 8,33 & 12 & 3,56 & 17 & 4,40 & 31 & 6,10 & 74 & 5,29 \\
\hline Öz Değerlendirme & 1 & 0,60 & 17 & 5,04 & 0 & 0,00 & 0 & 0,00 & 18 & 1,29 \\
\hline Problem Çözme & 2 & 1,19 & 3 & 0,89 & 1 & 0,26 & 10 & 1,97 & 16 & 1,14 \\
\hline Sorgulama & 0 & 0,00 & 0 & 0,00 & 1 & 0,26 & 7 & 1,38 & 8 & 0,57 \\
\hline Tahmin Etme & 8 & 4,76 & 16 & 4,75 & 32 & 8,29 & 39 & 7,68 & 95 & 6,8 \\
\hline Tasarlama & 1 & 0,60 & 0 & 0,00 & 2 & 0,52 & 3 & 0,59 & 6 & 0,43 \\
\hline Tartışma & 0 & 0,00 & 0 & 0,00 & 1 & 0,26 & 2 & 0,39 & 3 & 0,21 \\
\hline Yaratıcı Yazma & 1 & 0,60 & 3 & 0,89 & 8 & 2,07 & 5 & 0,98 & 17 & 1,22 \\
\hline Yorumlama & 0 & 0,00 & 0 & 0,00 & 0 & 0,00 & 2 & 0,39 & 2 & 0,14 \\
\hline Toplam & 168 & 100 & 337 & 100 & 386 & 100 & 508 & 100 & 1.399 & 100 \\
\hline
\end{tabular}

\begin{tabular}{|c|c|c|c|c|c|}
\hline Düşünme Becerileri & 5.sinif & 6.sinıf & 7.sinif & 8.sinif & Ortalama \\
\hline
\end{tabular}

\begin{tabular}{lllllllllll}
\hline Anlam Temelli & 32 & 5,38 & 32 & 6,71 & 22 & 3,99 & 30 & 6,54 & 116 & 5,57
\end{tabular}

Yapilandirma
Ayirt Etme

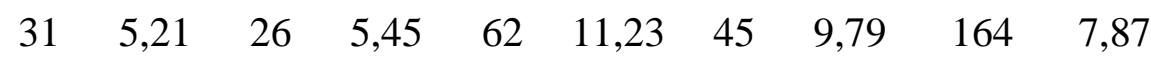

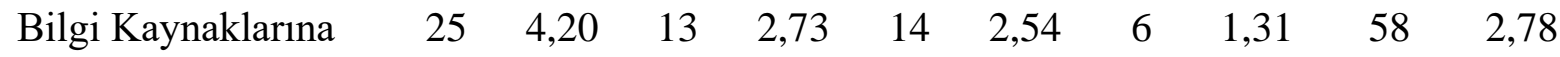
Ulaşma
$\begin{array}{lllllllllll}\text { Çıkarımda Bulunma } & 51 & 8,57 & 25 & 5,24 & 59 & 10,69 & 43 & 9,37 & 178 & 8,55\end{array}$
$\begin{array}{lllllllllll}\text { Çözümleme } & 12 & 2,02 & 8 & 1,68 & 8 & 1,45 & 6 & 1,31 & 34 & 1,63\end{array}$
$\begin{array}{lllllllllll}\text { Değerlendirme } & 16 & 2,69 & 4 & 0,84 & 9 & 1,63 & 8 & 1,74 & 37 & 1,78\end{array}$ 
Dönüştürme

Eşleştirme

Görsel/Grafik/Tablo

Okuma

Hatırlama

Karşılaştırma

Kural Uygulama

Neden-Sonuç İlişkisi

Kurma

$\begin{array}{lll}51 & 10,69 & 22\end{array}$

3,99

35

$0,87 \quad 25$

1,2

152,5

18

3,77

$1,63 \quad 10$

$2,18 \quad 52$

2,45

$6 \quad 1,01$

36.64160

$33,53 \quad 189$

$189 \quad 34,22 \quad 174 \quad 37,91$

$741 \quad 35,58$

$37 \quad 6,22 \quad 18 \quad 3,77$

19

$3,44 \quad 11$

2,40

$85 \quad 4,09$

$34 \quad 5,70$

$\begin{array}{llll}28 & 5,87 & 31 & 5,62\end{array}$

22

$4,79 \quad 115 \quad 5,56$

Öz Değerlendirme

50,8

Problem çözme

$4 \quad 0,6$

0

0,00

$4 \quad 0,72$

6

$1,31 \quad 15 \quad 0,72$

Sorgulama

$8 \quad 1,34$

$0,00 \quad 8$

1,45

4

$0,87 \quad 16 \quad 0,77$

Tasarlama

61,0

1,68

$3 \quad 0,54$

5

$1,09 \quad 24 \quad 1,15$

Tahmin Etme

$23 \quad 3,87 \quad 16 \quad 3,35 \quad 34 \quad 6,16$

22

4,79

4,56

Tartışma

$7 \quad 1,18 \quad 1 \quad 0,2$

6

1,09

$0 \quad 0,00$

$14 \quad 0,67$

Yaratıc1 Yazma

$\begin{array}{llll}16 & 2,69 & 32 & 6,7\end{array}$

$19 \quad 3,44 \quad 1$

$11 \quad 2,40$

78

3,74

Yorumlama

$4 \quad 0,67$

1,68

8

$1,45 \quad 10$

$10 \quad 2,18$

$30 \quad 1,44$

Toplam

$595 \quad 100$

$100 \quad 477$

10

55

$100 \quad 459$

$459 \quad 100$

$2.083 \quad 100$

Tablo 4'de görüldüğü gibidir. Ders kitaplarında 21 farklı düşünme becerisinin geliştirilmesinin amaçlandığı görülmektedir. Bu sayı, 1. ve 2. sınıfta 15;3.sınıfta 17; 4 . sinıfta 20; 5.sinıfta 21; 6.sınıfta 19; 7.sınıfta 21 ve 8.sinıfta 20'dir. İlkokul Türkçe ders kitaplarında yer alan etkinliklerin düşünme becerileri temelinde gösterdiği dağılıma yönelik ortalamalar incelendiğinde ilk üç sırada yer alan etkinliklerin sırayla hatırlama, çıkarımda bulunma ve eşleştirme düşünme becerilerine ait olduğu görülmektedir. Ancak burada ilk 
sırada yer alan hatırlama düşünme becerisi ile onu takip eden en yakın orana sahip olan düşünme becerisi arasındaki farkın yaklaşık \%40 olduğunu ifade etmek gerekmektedir. İncelemede çözümleme, sorgulama, dönüştürme, karşılaştırma, tasarlama, değerlendirme ve tartışma düşünme becerilerinin ortalamasının \%1'in altında olduğu görülmektedir. Bunun yanında yaratıcı yazma, problem çözme ve öz değerlendirme düşünme becerilerinin ortalamasının ise \%2'nin altında olduğu görülmektedir. Araştırma bulguları ilkokul Türkçe ders kitaplarında yer alan üst düzey düşünme becerileri kapsamında değerlendirilebilecek olan düşünme becerilerinin tamamına yakınının \%1 ve \%2'nin altında olduğunu göstermektedir.

Ortaokul Türkçe ders kitaplarında yer alan etkinliklerin düşünme becerileri temelinde gösterdiği dağglıma yönelik ortalamalar incelendiğinde ilk üç sırada yer alan etkinliklerin sırayla hatırlama, çıkarımda bulunma ve ayırt etme düşünme becerilerine ait olduğu görülmektedir. Ortaokul düzeyindeki kitaplarda da ilkokul düzeyindeki ile benzer bir durumun gözlendiği görülmektedir. Şöyle ki ilk sırada yer alan hatırlama düşünme becerisi ile ikinci sırada yer alan çıkarımda bulunma düşünme becerisi arasında yaklaşık \%23'lük bir fark vardır. İncelemede problem çözme, öz değerlendirme ve tartışma düşünme becerilerinin ortalamasının \%1'in altında olduğu görülmektedir. Bunun yanında çözümleme, sorgulama, dönüştürme, karş1laştırma, değerlendirme ve tasarlama düşünme becerilerinin ise \%2'nin altında bir orana sahip olduğu görülmektedir. Araştırma bulguları ortaokul Türkçe ders kitaplarında \%1 ve \%2'nin altında kalan oranlara sahip olan düşünme becerilerinin tamamına yakınının üst düzey düşünme becerileri kapsamında değerlendirilebilecek beceriler olduğunu göstermektedir.

Türkçe ders kitaplarında yer alan etkinliklerin sınıflar temelinde dağglımı incelendiğinde düşünme becerilerinin sınıf düzeyleri temelinde orantılı bir dağılım göstermediği görülmektedir. İncelenen ders kitaplarındaki etkinliklerin geliştirmeyi amaçladığı düşünme becerisi ortalamaları sınıflarla paralel bir görünüme sahip değildir. Örneğin üst düzey düşünme becerisi kapsamında değerlendirilebilecek olan problem çözme becerisini geliştirmeyi amaçlayan etkinlik sayısı ilkokul 1.sınıfta 2 iken 6. sınıfta problem çözme becerisini geliştirmeyi amaçlayan bir etkinliğe rastlanmamaktadır. Benzer bir biçimde yaratıcı düşünme becerisine bakıldığında, 6. 7. ve 8. sınıfta sınıf seviyesi yükseldikçe bu düşünme becerisini geliştirmeyi amaçlayan etkinlik sayısının azaldığı görülmektedir. 


\section{Araştırmanın İkinci Alt Problemine İlişkin Bulgular}

Araştırmanın ikinci alt probleminde "İlkokul ve ortaokul düzeyinde Türkçe ders kitaplarında yer alan etkinliklerde geliştirilmesi amaçlanan düşünme becerilerinin hangi yönüne odaklanılmıştır?” sorusunun cevabı aranmıştır. Aşağıda, Türkçe ders kitaplarında yer alan etkinliklerde geliştirilmesi amaçlanan 21 düşünme becerisinin hangi yönleriyle kullanıldığ etkinlik örnekleriyle birlikte incelenmektedir.

Türkçe ders kitaplarında yer alan etkinliklerde hatırlama düşünme becerisinin beş kullanım alanı vardır. Bunlar: Okuduğu, dinlediği ve izlediği içeriği anlatma; okuduğu, dinlediği ve izlediği içeriğe yönelik hatırlama düzeyindeki sorulara cevap verme; kavram, olgu, olay ve kişilere ilişkin bilgileri hatırlama; hayale ya da gerçeğe dayalı durum, olgu, olay, kişilere yönelik duygu, düşünce, hayal, his, istek, deneyim ve görüşlerini ifade etme; verilen metni bakarak yazma ve verilen metni ezberden okumadır.

Türkçe ders kitaplarında yer alan etkinliklerde çıkarımda bulunma düşünme becerisinin beş kullanım alanı vardır. Bunlar: Okuduğu, dinlediği/izlediği içeriğin başlık, ana fikir, ana düşünce, ana duygu, tema ve konusunu belirleme; hayali ya da olası gerçek durumlar temelinde çıkarımlarda bulunma; okuduğu dinlediği ve izlediklerinde geçen karakterlerin özelliklerine yönelik çıkarımlarda bulunma; sözcük ya da söz gruplarının (deyim, atasözü), söz sanatlarının, geçiş ve bağlantı ifadelerinin dinlediği/izlediği ve okuduğu içeriğe olan katkısına yönelik çıkarımlarda bulunma ve dil kurallarının (yazım, noktalama) nedenlerine ilişkin çıkarımda bulunmadır.

Türkçe ders kitaplarında yer alan etkinliklerde eşleştirme düşünme becerisinin dört kullanım alanı vardır. Bunlar: Kavramlarla anlamları eşleştirme; noktama işaretlerinin kullanım alanlarını örnekleriyle eşleştirme; eş anlamlı ve zıt anlamlı kelimeleri eşleştirme ve görsellerle anlamlarını eşleştirmedir.

Türkçe ders kitaplarında yer alan etkinliklerde ayırt etme düşünme becerisinin iki kullanım alanı vardır. Bunlar: Okuduğu, dinlediği/izlediği içerikteki ifade edilen kişilik özelliklerini ayırt etme ve tür, yapı, biçim ve anlamsal özellikler açısından istenilen özelliği ayırt etmedir.

Türkçe ders kitaplarında yer alan etkinliklerde tahmin etme düşünme becerisinin dört kullanım alanı vardır. Bunlar: Dinleyeceği, okuyacağı metnin görsel ve başlığından hareketle dinlenilecek ya da okunulacak olan metin hakkında tahminde bulunma; dinlediği, okuduğu metnin devamını tahmin etme; dinlediği/izlediği, okuduğu metinlerde ifade edilen 
durumlar üzerinde tahminde bulunma ve anlamını bilmediği kelime, kelime grubu, deyim ve atasözlerinin anlamını tahmin etmedir.

Türkçe ders kitaplarında yer alan etkinliklerde kural uygulama düşünme becerisinin üç kullanım alanı vardır. Bunlar: İstenilen özellikteki kelime ve kuralı (noktalama işareti, ses olayları) kullanarak cümle kurmak; açıklanan ve örneklendirilen kuralı yerine getirme ve okuduğu cümlelerde var olan anlamsal ve biçimsel bozuklukların yönergede açıklandığı gibi düzeltilmesidir.

Türkçe ders kitaplarında yer alan etkinliklerde görsel okuma düşünme becerisinin üç kullanım alanı vardır. Bunlar: Görseli anlatma ve yorumlama; görsele yönelik soruları cevaplandırma ve birden fazla görseli kullanarak hikâye/diyalog/fikra yazmadır.

Türkçe ders kitaplarında yer alan etkinliklerde neden sonuç ilişkisi kurma düşünme becerisinin iki kullanım alanı vardır. Bunlar: Okuduğu, dinlediği ve izlediklerinin nedenlerine ilişkin akıl yürütme ve okunan, dinlenen/izlenen içeriklerde ifade edilen birbirinden farklı iki durum arasında neden sonuç ilişkisi kurmadır.

Türkçe ders kitaplarında yer alan etkinliklerde yaratıcı yazma düşünme becerisinin beş kullanım alanı vardır. Bunlar: Hayali bir duruma yönelik izlenimlerini anlatma; verilen bir konu temelinde şiir, hikâye, masal, fabl, mektup, telefon görüşmesi yazma; anlatılan bir olayı farklı biçimde kurgulama; hikâye, masal, fikra tamamlama ve slogan yazmadır.

Türkçe ders kitaplarında yer alan etkinliklerde değerlendirme düşünme becerisinin iki kullanım alanı vardır. Bunlar: Metin ve görselleri birtakım ölçütler temelinde değerlendirme ve okuduğu, dinlediği/izlediği metinlerde ifade edilen olay/durum/kişilikleri yönergede ifade edilenler temelinde değerlendirmedir.

Türkçe ders kitaplarında yer alan etkinliklerde tasarlama düşünme becerisinin beş kullanım alanı vardır. Bunlar: Bir problemin çözümüne yönelik ürün/proje tasarlama; oyun/oyun alanı tasarlama; grafik tasarlama; imza tasarlama ve alet ve kullanma kılavuzu tasarlamadir.

Türkçe ders kitaplarında yer alan etkinliklerde öz değerlendirme düşünme becerisinin bir kullanım alanı vardır. Bu: Birtakım ölçütler ile okuma, yazma, konuşma becerilerini değerlendirmedir.

Türkçe ders kitaplarında yer alan etkinliklerde anlam temelli yapılandırma düşünme becerisinin üç kullanım alanı vardır. Bunlar: Belirli bir konu bağlamında verilen yönergeleri 
E, Bayrak Özmutlu ve P, Kanık Uysal/ Pamukkale Üniversitesi Eğitim Fakültesi Dergisi, 52, 518-543 533 uygun olarak hazırlıklı bir konuşma hazırlama, yapma; belirli bir konu bağlamında bilgilendirici bir metin yazma ve okuduğu, dinlediği ve izlediği içeriği özetlemedir.

Türkçe ders kitaplarında yer alan etkinliklerde bilgi kaynaklarına ulaşma düşünme becerisinin bir kullanım alanı vardır. Bu: Verilen bir konuya ilişsin yardımla ya da bağımsız olarak birincil ya da ikincil bilgi kaynaklarına ulaşmasıdır.

Türkçe ders kitaplarında yer alan etkinliklerde çözümleme düşünme becerisinin dört kullanım alanı vardır. Bunlar: Bir işi işlem yönergelerini ayırmak; yazılı metni unsurlarına ayırmak; varlık kadrosunu çözümlemek ve cümleyi ögelerine ayırmaktır.

Türkçe ders kitaplarında yer alan etkinliklerde problem çözme düşünme becerisinin iki kullanım alanı vardır. Bunlar: Çevresinde yaşanan problemleri fark etme, tanımlama, akıl yürütme ve hayali bir kahramanın sosyal ve duygusal problemlerinin çözümüne yönelik akıl yürütmedir.

Türkçe ders kitaplarında yer alan etkinliklerde sorgulama düşünme becerisinin iki kullanım alanı vardır. Bunlar: Okuduğu, dinlediği/izlediği ile ilgili sorular oluşturma ve okuduğu, dinlediği/izlediği içeriğin tutarlılığını sorgulamadır.

Türkçe ders kitaplarında yer alan etkinliklerde dönüştürme düşünme becerisinin dört kullanım alanı vardır. Bunlar: Okuduğu, dinlediği/izlediği metni canlandırma; uzamsal düşünme; bir türü farklı bir türe dönüştürme ve grafik oluşturmadır.

Türkçe ders kitaplarında yer alan etkinliklerde karş1laştırma düşünme becerisinin dört kullanım alanı vardır. Bunlar: Okuduğu, dinlediği/izlediği metinde geçen kahramanların karakter özelliklerini karşılaştırma; okuduğu, dinlediğgi/izlediği metinde yer alan ögelerin fiziksel özelliklerini karşılaştırma; okuduğu, dinlediği/izlediği metinleri konu, tür, biçim özellikleri açısından karşılaştırma ve gerçeğe dayalı ya da olası kurgular temelinde yaratılmış iki durumu karşılaştırmadır.

Türkçe ders kitaplarında yer alan etkinliklerde yorumlama düşünme becerisinin bir kullanım alanı vardır. Bu: Özdeyiş, atasözü, deyim, deyiş, söz öbeği, metafor, dize gibi unsurların anlamlarına ilişkin açıklamalarda bulunmadır.

Türkçe ders kitaplarında yer alan etkinliklerde tartışma düşünme becerisinin bir kullanım alanı vardır. Bu: Tartışmaya açık durum, koşul, şart, problem, olasılıkların olası sebep ve sonuçları üzerinde fikir üretme, fikirlerini yazılı ya da sözlü olarak ifade etmedir. 


\section{Tartışma ve Sonuç}

$\mathrm{Bu}$ araştırma ders kitaplarında yer alan dil becerileri etkinliklerinin düşünme becerileri geliştirme konusundaki durumunu belirlemeyi amaçlamaktadır. $\mathrm{Bu}$ kapsamda 1-8. sınıf Türkçe ders kitaplarında yer alan toplam 3.452 etkinlik incelenmiştir. Etkinlikler öğrencilerde geliştirmeyi amaçladığı düşünme becerileri temelinde analiz edilmiştir. Araştırmanın sunduğu veriler, dil becerilerinin düşünme becerileri geliştirme konusunda sahip olduğu potansiyelin ders kitapları açısından hangi oranda doğru ve etkili bir biçimde kullanıldığının sorgulanmasını mümkün kılmaktadır. Araştırmada Türkçe ders kitapları ile 21 farklı düşünme becerisinin geliştirilmesinin amaçlandığı görülmektedir. İlkokul düzeyinde ilk üç sırada yer alan etkinliklerin sırayla hatırlama, çıkarımda bulunma ve eşleştirme; ortaokul düzeyinde yer alan etkinliklerin sırayla hatırlama, çıkarımda bulunma ve ayırt etme düşünme becerileri olduğunu göstermektedir.

Araştırma bulguları ilkokul ve ortaokul düzeyinde Türkçe ders kitaplarında yer alan ve diğerlerine oranla daha karmaşık zihinsel işlemler gerektiren düşünme becerilerinin neredeyse tamamının sahip olduğu oranın \%2'nin altında olduğunu göstermektedir. Alanyazında bu konuda yapılmış çok sayıda araştırma çalışmanın bu bulgusunu destekler niteliktedir. Örneğin Çeçen ve Kurnaz (2015), araştırmasında Türkçe ders kitaplarında değerlendirme ve yaratma basamağında yer alan soruların oranının \%1 olduğunu belirlemiştir. Benzer şekilde Şengül (2005) metne dayalı sorular üzerine yaptığı araştırmasında, alt düzey düşünme becerilerinden üst düzeydekilere doğru gidildikçe, soru sayısının büyük oranda düştüğü sonucuna ulaşmıştır. Sarar-Kuzu (2013) Türkçe ders kitaplarındaki metin altı sorularından üst düzey zihinsel süreçlere ait soruların düşük bir orana sahip olduğunu ifade etmiştir. Başka bir araştırmada ders kitaplarında alt düzey bilişsel beceri basamakları olan hatırlama, anlama ve uygulama lehine dengesizlik olduğu dile getirilmektedir (Dolunay ve Savaş, 2016). Küçükaydın ve İşcan (2017) ise Türkçe öğrenci çalışma kitabında yer alan etkinliklerin öğrenenlere temel düzeyde beceriler kazandırmaya yönelik olduğu sonucuna ulaşırken Yağmur (2009) Türkçe ders kitaplarının öğrencilerin üst düzey bilişsel becerilerini geliştirmediğini ifade etmiştir. Çevik ve Güneş (2017) Türkçe ders kitabında yer alan etkinliklere yönelik olarak yaptığı araştırmasında dil bilgisi etkinliklerinin otomatik tekrarları içerdiği, bazılarının çoktan seçmeli, cümle çevirisi, tanımlama, eş anlamlıları bulma vb. içerikte hazırlandığını ortaya çıkarmıştır. Bu tür etkinliklerin çabuk ezberlendiği ve dil öğrenmeye fazla katkısı olmadığı bilinmesine rağmen yaygın kullanıldığı ifade edilmektedir (Çevik ve Güneş, 2017). 
E, Bayrak Özmutlu ve P, Kanık Uysal/ Pamukkale Üniversitesi Eğitim Fakültesi Dergisi, 52, 518-543 535

Düşünme becerilerine yönelik bulgulara daha detaylı olarak bakılacak olursa, ders kitaplarında öğrencileri araştırma ve incelemeye yönlendiren etkinlilerin sadece "araştırınız" yönergesi ile biten soru cümleleri olarak yer aldı̆̆ını belirtmek gerekmektedir. Etkinlikler, bu haliyle araştırma ve inceleme sürecinin adımlarını ve gerekliliklerine yönelik hiçbir yönlendirme ya da aşamalandırma içermemektedir. Bunun yanında temalar temelinde sarmal bir anlayış içinde bu beceriyi geliştirmeye yönelik yapılandırılmış hiçbir etkinliğe rastlanmamaktadır. Etkinliklerde öğrencilerin hangi kaynaklardan bilgi toplayabileceği, bu bilgilerin geçerlik ve güvenirliği konusunda ne tür sorgulamalar yapabileceği ya da önlemler alabileceği, bu bilgileri nasıl kaydedeceği ve rapor haline getireceğine yönelik hiçbir yönlendirme bulunmamaktadır. Bunun yanında öğrencileri araştırma ve incelemeye yönlendiren etkinlik sayısının da oldukça düşük yüzdelere sahip olduğu (ilkokul \%2.1, ortaokul, \%2.78) görülmektedir.

Araştırmada eleştirel düşünme kapsamında değerlendirilebilecek olan sorgulama ve problem çözme düşünme becerilerinin oranının \%1'in altında olduğu görülmüştür. Benzer bir bulguyu bulan Benzer (2019) Türk eğitim sistemine 2006 Türkçe Dersi Öğretim Programı ile girmiş olmasına ve aradan geçen 14 yıla rağmen ders kitaplarında eleştirel düşünme gibi becerilerin kullanılmamasının düşündürücü olduğu yorumunda bulunmuştur. Dolunay ve Savaş'ın (2016) bulgularında ise ortaokul 6, 7 ve 8. sınıf Türkçe dersi öğrenci çalışma kitaplarında eleştirel düşünme becerisini geliştirebilecek etkinlikler olmadığı tespit edilmiştir. Öğretmenlerin ders kitaplarına yönelik görüşlerinin incelendiği başka bir araştırmada (Gün, 2012), öğretmenlerin \%65'inin okuma etkinliklerini, öğrencinin eleştirel ve yaratıcı düşünme gücünü geliştirme konusunda yetersiz buldukları ortaya çıkmıştır. Temizkan (2014) araştırmasında Türkçe ders kitaplarındaki metinlerde problem çözme becerisine çok az oranda yer verilmesinin düşündürücü olduğu yorumunda bulunmuş ve eleştirel düşünmenin ders kitaplarında çok düzensiz bir dağılım gösterdiğini ifade etmiştir. Türkçe ders kitaplarındaki metinlere yönelik başka bir araştırmada, Başoğlu ve Mutlu (2012), 7. ve 8. sınıf Türkçe ders kitaplarında yer alan metinlerin çoğunlukla; öğrenciyi düşündürmekten uzak, merak duygusunu kamçılamayan ve bilgilerin hazır olarak sunulduğu metinler olduğunu ifade etmiştir. Benzer bir çalışmayı Türkçe Dersi Öğretim Programı üzerinde yürüten Söylemez (2018) ise eleştirel düşünmenin az sayıda yer aldığ kazanımlarda yaratıcı düşünme ve problem çözmenin ihmal edildiği yorumunu yapmıştır.

Araştırmada yaratıcı düşünme becerilerini geliştirmeyi amaçlayan kazanımların tamamına yakınının yaratıcı yazma konusunda olduğu görülmüştür. Bunun yanında bu 
kapsama giren etkinliklerin öğrencilerde yaratıcı düşünme becerilerini geliştirme üzerinde özel olarak tasarlanmış etkinlikler olmadığını ifade etmek önemlidir. Bu etkinlikler daha çok öğrencilerin yaratıcı yazma çalışmalarını gerçekleştirebilmelerini amaçlayan yönergelerden oluşmaktadır. Etkinliklerin öncesinde ya da sonrasında yaratıcı düşünme becerilerini geliştirmeyi amaçlayan yönlendirme, değerlendirme ya da bilgilendirmeler yer almamaktadır. $\mathrm{Bu}$ yönüyle söz konusu etkinliklerin öğrencilerin yaratıcı düşünme becerilerini sistematik bir yolla geliştirme özelliğinden yoksun olduğu görülmüştür. Analizler ders kitaplarında yaratıcı düşünme becerisini geliştirmeyi amaçlayan etkinliklerin oranlarının ilkokulda \%3.38, ortaokulda \%4.28 olduğunu göstermiştir. Bu konuda bir inceleme gerçekleştiren Temizkan (2014) Türkçe ders kitaplarında yaratıcı düşünmenin oldukça yetersiz bir oranda yer aldığını ifade etmiştir. Dolunay ve Savaş (2016) ise dinleme etkinlikleri içerisinde yaratma basamağına ait etkinliklerin sayısının çok düşük olduğu açıklamasında bulunmuş, Çeçen ve Kurnaz (2015) Türkçe ders kitaplarında yaratma basamağında yeterli sayıda soru bulundurulması gerektiğini ifade etmiştir.

Araştırmada birtakım düşünme becerilerinin kendi aralarında ve sınıflar temelinde dengeli bir dağılıma sahip olmadığı görülmüştür. Türkçe ders kitaplarında gözlenen bu durumun bilimsel bir dayanağının olup olmadığının sorgulanması gerekmektedir. Benzer bulguyu dile getiren Dolunay ve Savaş (2016), dinleme etkinliklerinin dağılımında bilişsel beceri basamakları arasında uçurum olduğunu ifade etmiştir. Yine etkinlikleri geliştirmeyi amaçladığı zekâ türleri açısından inceleyen Bayram ve Baki (2014) araştırmasında etkinliklerin orantılı bir dağılıma sahip olmadığını tespit etmiştir. İncelemede \%60.37 sözeldil zekâ, \%15 mantık-matematik zekâ alanlarında yoğunluk olduğu ifade edilmiştir (Bayram ve Baki, 2014). Türkçe ders kitabındaki kazanımları beceriler temelinde inceleyen araştırmalar da benzer bulguları yansıtmaktadır (Büyükalan ve Yıldırım, 2019; BayrakÖzmutlu, 2020).

Ders kitaplarındaki etkinliklerle ilgili bulgulardan bir diğeri de etkinlik türlerindeki tek tipliliktir. Etkinliklerin yaklaşık yarısının üç düşünme becerisine odaklanmasının yanında, 1.ve 8. sınıfa kadar benzer yönerge ve açıklamalardan oluştuğu gözlenmiştir. Örneğin çıkarımda bulunma düşünme becerisi ile ilgili etkinliklerin tamamına yakını konu bulma, ana fikri/ana duyguyu bulmaya yönelik etkinliklerden oluşmakta her sınıfta aynı yönergeler bulunmaktadır. Araştırmasında ders kitaplarında PISA'da çokça sorulan değerlendirme ve derinlemesine çözümleme düzeyindeki sorularla karşılaşılmadığını ifade eden Benzer'in (2019) bulguları da bu çalışmanın bulgularıyla aynı yöndedir. Aynı 
E, Bayrak Özmutlu ve P, Kanık Uysal/ Pamukkale Üniversitesi Eğitim Fakültesi Dergisi, 52, 518-543 537 çalışmada ders kitaplarındaki metin altı soruların bilgiye ulaşma ve bilgiyi hatırlama düzeyinde yoğunlaştığı ifade edilmektedir. Çeçen ve Kurnaz (2015) da ders kitaplarındaki tema değerlendirme sorularının ağırlıklı olarak bir türde olduğunu belirterek bu durumu Türkçe Dersi Öğretim Programı'nın bireysel farklılıkları dikkate alan ve ölçmede farklı değerlendirme yöntemlerinin benimsendiği anlayışı yeterince yansıtmadığı yönünde yorumlamıştır. Dağ (2007) ise ders kitaplarında yer alan etkinliklerin tek düze olduğunu, birbirine benzediği ve tekrarlandığını saptamıştır. Çevik ve Güneş (2017) de araştırmasında dil bilgisi etkinliklerinde gözlenen tek tipliliğe yönelik değerlendirmelerde bulunmuştur. Etkinliklerdeki tep tipliliğe yönelik bir diğer bulgu Kılıç, Baki ve Yıldırım'a (2014) aittir. Araştırmada ders kitabında ağırlıklı olarak sözel-dil ve mantık-matematik zekâsına dayalı etkinliklere yer verildiği diğer zekâ alanlarına ise gereken önemin verilmediği ifade edilmiştir. Coşkun (2013) da yaptığı çalışmasında tek yanıtlı sorular dışında okuyucunun farklı metinlerdeki bilgileri ilişkilendirerek yanıtlayabileceği soru türlerine hiçbir sınıf düzeyinde yer verilmediğini, etkinliklerin üst düzey okuma becerilerini kapsamadığını belirtmiştir. Bozkurt, Uzun ve Lee (2015) ise Türkçe ders kitaplarındaki en fazla rastlanan soru tiplerinin bilgiye ulaşma-hatırlama düzeyinde olduğunu belirlemişlerdir.

Araştırma bulgularına dayalı olarak şu önerilerde bulunmak mümkündür. Talim Terbiye Kurulu'nun ders kitabı değerlendirme ölçütlerine düşünme becerilerinin de dâhil edilmelidir. Ders kitaplarındaki etkinliklerin başında öğretmenlerin yürüteceği çalışmalara k1lavuzluk etmesi amacıyla etkinliğin hangi kazanım ile ilgili olduğu ve hangi düşünme becerisini geliştirmeyi amaçladığına yönelik yönerge ve açıklamalara yer verilmesi önemli bir gerekliliktir. Etkinlikler geliştirilirken Türkçe dersinin düşünme becerilerini geliştirme konusunda sahip olduğu olanakların dikkate alınması önem taşımaktadır. Etkinliklerde temele alınan her kazanımın ve dil becerisinin düşünme becerisini geliştirme konusundaki potansiyeli dikkate alınmalıdır. Ders kitapları 1.sınıftan 8.sınıfa kadar ortak bir anlayış içinde birbirini tamamlayan sarmal bir anlayış içinde geliştirilmelidir. Her düşünme becerisi 1.sınıftan 8.sınıfa kadar öğretme ve öğrenme ilkeleri temelinde planlanmış etkinliklerle geliştirilmelidir. Üst düzey düşünme becerileri çok sayıda düşünme becerisinin eş zamanlı ya da sıralı olarak kullanımını gerektirdiğinden söz konusu düşünme becerisinin doğasına uygun bir biçimde etkinlikler; hazırlık, uygulama ve değerlendirme adımları altında gerekli yönlendirme ve bilgilendirmeler içermelidir. Üst düzey düşünme becerilerinin sadece bir soru yönergesi ile geliştirilemeyeceğinin farkında olunmalı ve ders kitaplarının hazırlanma süreci bu kapsamda değerlendirilmeli ve yönlendirilmelidir. Öğretmene kılavuzluk eden 
538 E, Bayrak Özmutlu ve P, Kanık Uysal/ Pamukkale Üniversitesi Eğitim Fakültesi Dergisi, 52, 518-543, 2021

doğru bir anlayış içinde yapılandırılmış bir ders kitabının üst düzey düşünme becerilerinin gelişimi konusunda sahip olduğu güç ve olanaklar çok fazladır.

Etik Kurul İzin Bilgisi: Bu çalışmada ölçek ve anket kullanılmadı̆̆ı için etik kurul iznine ihtiyaç duyulmamıştır.

Çıkar Çatışması: Yazarların beyan edeceği bir çıkar çatışması yoktur.

Yazar Katkısı: Birinci yazar, problem durumunun belirlenmesi, verilerin toplanması ve verilerin analizi aşamalarında; ikinci yazar, çalışma kapsamının belirlenmesi, problem durumunun belirlenmesi ve verilerin analizi aşamalarında çalışmaya katkı sağlamıştır. Öte yandan tüm yazarlar, alanyazın incelemesi, tartışma ve raporlama aşamalarında çalışmaya katkı sağlamıştır. 


\section{Kaynakça}

Arslan, A. ve Engin, A. O. (2019). 5. sınıf Türkçe dersi öğretim programının öğretmen görüşlerine göre değerlendirilmesi. Disiplinlerarası Eğitim Araştırmaları Dergisi, 3(5), 19-39.

Başoğlu, N. ve Mutlu, B. (2012). İlköğretim Türkçe ders kitaplarında yer alan metinlerin eleştirel düşünme eğitimine uygunluğu. Kastamonu Ĕ̆itim Dergisi, 20(3), 983-998.

Bayrak-Özmutlu, E. (2020). Ana dili öğretim programlarında yer alan kazanımların zihinsel beceriler temelinde gösterdiği dağılımın incelenmesi. Çukurova Üniversitesi Ĕ̆itim Fakültesi Dergisi, 49 (1), 185-224.

Bayram, B. ve Baki, Y. (2014). Ortaokul 6. sınıf Türkçe dersi öğretmen kılavuz kitabının çoklu zekâ kuramı açısından değerlendirilmesi. Dil ve Edebiyat Eğitimi Dergisi, 9, 113-147.

Benzer, A. (2019). Türkçe ders kitaplarının PISA okuma yeterlik düzeyleri ile imtihanı. Okuma Yazma Ĕgitimi Araştırmaları, 7(2), 96-109.

Bozkurt, B. Ü., Uzun, G. L., ve Lee, Y. (2015). Korece ve Türkçe ders kitaplarındaki metin sonu sorularının karşılaştırılması: PISA 2009 sonuçlarına dönük bir tartışma. International Journal of Language Academy, 3(9), 295-313.

Büyükalan, F. S. ve Yıldırım, N. (2019). Ortaokul Türkçe dersi öğretim programı kazanımlarının revize edilmiş Bloom Taksonomisine göre analizi. Elementary Education Online, 18(4), 1551-1573.

Creswell, J. W., \& Miller, D. L. (2000). Determining validity in qualitative inquiry. Theory into Practice, 39(3), 124-130.

Coşkun, Y. D. (2013). Türkçe ders kitaplarının PISA sınavı okuma ölçütleri açısından incelenmesi. Mehmet Akif Ersoy Üniversitesi Eğitim Fakültesi Dergisi, 13(26), 2243.

Çalışkan, G. (2016). Türkçe dersi öğretim programı ve Türkçe ders kitapları: 5. sınıf Türkçe ders kitabına yönelik bir inceleme. Ana Dili Ĕ̆itimi Dergisi, 4(2), 200-214.

Çarkıt, C. (2019). 2018 Türkçe dersi öğretim programı çerçevesinde hazırlanan 8. sınıf Türkçe ders kitabının değerlendirilmesi. Electronic Journal of Social Sciences, 18(71), 1368-1376. 
540 E, Bayrak Özmutlu ve P, Kanık Uysal/ Pamukkale Üniversitesi Eğitim Fakültesi Dergisi, 52, 518-543, 2021

Çeçen, M. A. ve Kurnaz, H. (2015). Ortaokul Türkçe dersi öğrenci çalışma kitaplarındaki tema değerlendirme soruları üzerine bir araştırma. Karadeniz Sosyal Bilimler Dergisi, 7(02). https://dergipark.org.tr/tr/pub/ksbd/issue/16219/169872

Çevik, A. ve Güneş, F. (2017). Türkçe ders kitaplarındaki etkinliklerin incelenmesi. Ana Dili Ĕ̈itimi Dergisi, 5(2), 272-286.

Dağ, Ö. (2007). Illköğretim Türkçe dersi programlarına (1981-2005) eğitimsel dilbilim açısından eleştirel bir bakış [Yayınlanmamış Yüksek Lisans Tezi]. Ankara Üniversitesi Sosyal Bilimler Enstitüsü Dilbilim Anabilim Dalı, Ankara.

Demir, H. ve Baş, Ö. (2019). Türkçe ders kitabındaki metinlerin eleştirel düşünme ölçütlerini karşılaması üzerine nitel bir araştırma. Uluslararası Türkçe Edebiyat Kültür Ĕ̌gitim (TEKE) Dergisi, 8(2), 983-1006.

Deniz, K., Tarakcı, R., ve Karagöl, E. (2019). Okuma kazanımları açısından ortaokul Türkçe ders kitaplar1. Ana Dili Ĕgitimi Dergisi, 7(3), 688-708.

Dolunay, S. K. ve Savaş, Ö. (2016). Ortaokul Türkçe ders kitaplarındaki dinleme etkinliklerinin üst düzey bilişsel beceriler açısından değerlendirilmesi. Eğitimde Kuram ve Uygulama, 12(1), 122-157.

Durukan, E. ve Demir, E. (2017). 6, 7 ve 8. sınıf Türkçe dersi öğrenci çalışma kitaplarındaki etkinliklerin Bloom'un yenilenmiş taksonomisine göre sınıflandırılması. Uluslararası Türkçe Edebiyat Kültür Eğitim (TEKE) Dergisi, 6(3), 1619-1629.

Ekinci-Çelikpazu, E. ve Aktaş, E. (2011). MEB 6, 7 ve 8. sınıf Türkçe ders kitaplarında yer alan metinlerin değer iletimi açısından incelenmesi. Turkish Studies, 6(2), 413-424.

Erdoğan, T. (2014). İlkokul 1-4. Sınıflar Türkçe dersi öğrenci çalışma kitaplarındaki etkinliklerin yaratıcı düşünme becerisi açısından incelenmesi. Dicle Üniversitesi Ziya Gökalp Ĕ̌itim Fakültesi Dergisi, (23), 25-58.

Fogarty, R., \& McTighe, J. (1993). Educating teachers for higher order thinking: The threestory intellect. Theory into Practice, 32, 161-169.

Güler, A., Halıcıoğlu, M. B., ve Taşğın, S. (2013). Sosyal bilimlerde nitel araştırma yöntemleri. Ankara: Seçkin Yayıncılık. 
E, Bayrak Özmutlu ve P, Kanık Uysal/ Pamukkale Üniversitesi Eğitim Fakültesi Dergisi, 52, 518-543 541

Gültekin, H. (2019). Türkçe dersi öğrenci çalışma kitaplarının 21. yüzyıl becerileri açısından incelenmesi [Yayımlanmamış Yüksek Lisans Tezi]. Balıkesir Üniversitesi Sosyal Bilimler Enstitüsü, Balıkesir.

Gün, M. (2012). İlköğretim ikinci kademe Türkçe dersi okuma etkinliklerinde karşılaşılan sorunlar. Electronic Turkish Studies, 7(4), 1961-1977.

Güneş, F. (2012). Testlerden etkinliklere Türkçe öğretimi. Dil ve Edebiyat Eğitimi Dergisi, 1(1), 31-42.

Güneş, F. (2017). Türkçe öğretiminde etkinlik yaklaşımı. Ana Dili Eğitimi Dergisi, 5(1), 4864.

Karadağ, Ö. (2019). Aynı sınıf düzeyi için hazırlanan Türkçe ders kitaplarının ortak sözvarlığı açısından karşılaştırılması. Ana Dili Eğitimi Dergisi, 7(4), 1130-1140.

Karadağ, Ö. ve Tekercioğlu H. (2019). Türkçe ders kitaplarındaki bilişsel ve üstbilişsel işlevlere dair bir durum tespiti. Mersin Üniversitesi Eğitim Fakültesi Dergisi, 15(3), 628-64.

Kılıç, L. K., Baki, Y., ve Bayram, B. (2014). Ortaokul 8. sınıf Türkçe dersi öğretmen kılavuz kitabındaki etkinliklerin çoklu zekâ kuramı ile örtüşme düzeyi. Ana Dili Ĕ̈itimi Dergisi, 2(2), 72-89.

Kurudayığlu, M. ve Yaşar, F. Ö. (2014). 6. sınıf Türkçe dersi öğretmen kılavuz kitaplarındaki dinleme metinlerinin dinleme yöntem ve teknikleri açısından incelenmesi. Ana Dili Ĕ̈itimi Dergisi, 2(2), 1-14.

Kuzu, T. S. (2013). Türkçe ders kitaplarındaki metin altı sorularının yenilenmiş Bloom taksonomisindeki hatırlama ve anlama bilişsel düzeyleri açısından incelenmesi. Cumhuriyet Üniversitesi Edebiyat Fakültesi Sosyal Bilimler Dergisi, 37(1), 58-76.

Küçükaydın, M. A. ve İşcan, A. (2017). İlköğretim 3. sınıf Türkçe ders kitapları ve öğretmen kılavuz kitabının yapılandırmacı öğrenme yaklaşımına uygunluk düzeyi. Ana Dili Ĕ̈itimi Dergisi, 5(1), 1-13.

Marzano, R. J. (2001). Designing a new taxonomy of educational learning outcomes. Thousand Oak, CA: Corwin Press, Inc.

Mutluer, C. (2013). Sosyal bilgiler programlarında yer alan beceriler hakkında sosyal bilgiler öğretmen görüşleri (İzmir Menemen Örneği), Turkish Studies, 8(7), 355-362. 
542 E, Bayrak Özmutlu ve P, Kanık Uysal/ Pamukkale Üniversitesi Eğitim Fakültesi Dergisi, 52, 518-543, 2021

Ocak, G. ve Dai, A. (2010). İlköğretim dördüncü sınıf Türkçe ders ve çalışma kitaplarının yapılandırmacı öğrenme anlayışına göre değerlendirilmesi. Türkiye Sosyal Araştırmalar Dergisi, 3, 91-108.

Özbay, M. (2003). Türkçe öğretiminde hedef-araç ilişkisinin ders kitabı örneğinde değerlendirilmesi. Türklük Bilimi Araştırmaları, 13, 59-69.

Özkanal, Ü. ve Bayrak, E. (2016). İlkokul Türkçe çalışma kitaplarındaki dinleme etkinliklerinin zihinsel becerilere göre dağılımı. Kırşehir Eğitim Fakültesi Dergisi, 17(1), 201-220.

Patton, M. Q. (2014). Nitel araştırma ve değerlendirme yöntemleri. (Çev. Ed. M. Bütün ve S. B. Demir). Pegem Akademi Yayınları, Ankara.

Resnick, L. B. (1987). The thinking curriculum. Washington, DC: National Academy Press.

Savaşkan, V. (2016). Ortaöğretim 9. sınıf Türk Edebiyatı ders kitaplarındaki metin altı soruları üzerine bir inceleme. Hitit Üniversitesi Sosyal Bilimler Enstitüsü Dergisi, 9(2), 821-836.

Scott, J., \& Marshall, G. (2015). A dictionary of sociology ( $3^{\text {th }}$ ed.). London: Oxford University Press.

Soysal, T. ve Kurudayığlu, M. (2019). Study of ministry of education 9th grade Turkish language and literature coursebook in terms of the skills and capabilities in the 2017 program. Mehmet Akif Ersoy Üniversitesi Eğitim Fakültesi Dergisi, 54, 184-199.

Söylemez, Y. (2018). 2018 Türkçe dersi öğretim programındaki kazanımların üst düzey düşünme becerileri açısından değerlendirilmesi. Atatürk Üniversitesi Türkiyat Araştırmaları Enstitüsü Dergisi, 63, 345-384.

Süğümlü, Ü., Mutlu, H. H., ve Çinpolat, E. (2019). Ortaokul Türkçe dersi öğretmen kılavuz kitaplarının kullanılması ve kullanılmamasına ilişkin bir durum çalışması. Abant İzet Baysal Üniversitesi Eğitim Fakültesi Dergisi, 19(4), 1667-1681.

Şengül, M. (2005). İlköğretim 8. Sinıf Türkçe ders kitaplarındaki metinlere dayalı olarak hazırlanan sorular üzerine bir inceleme [Yayımlanmamış Yüksek Lisans Tezi]. Fırat Üniversitesi Sosyal Bilimler Enstitüsü, Elazığ. 
E, Bayrak Özmutlu ve P, Kanık Uysal/ Pamukkale Üniversitesi Eğitim Fakültesi Dergisi, 52, 518-543 543

Temizkan, M. (2014). Ortaokul Türkçe ders kitaplarının Türkçe dersi öğretim programındaki temel beceriler açısından incelenmesi. Ana Dili Eğitimi Dergisi, 2(1), 49-72.

Tosunoğlu, M. ve Demir, E. (2014). MEB Yayınları 5. Sınıf Türkçe dersi öğrenci çalışma kitabındaki etkinliklerin dil öğrenme alanlarına ve taksonomiye göre değerlendirilmesi. Millî Ĕgitim Dergisi, 44(203), 74-83.

Uçgun, D. (2018). 1-5. sınıf Türkçe ve Türk kültürü çalışma kitaplarındaki Türkçe dersi etkinliklerinin programdaki kazanımlara göre değerlendirilmesi. Uluslararası Türkçe Edebiyat Kültür Eğitim (TEKE) Dergisi, 7(2), 1148-1160.

Ulum, H. ve Taşkaya, S. M. (2019). İlkokul 2, 3 ve 4. sınıf Türkçe ders ve çalışma kitaplarında yer alan etkinliklerin yenilenmiş Bloom taksonomisine göre incelenmesi. Kastamonu Ĕ̆itim Dergisi, 27(1), 107-118.

Yağmur, K. (2009). Türkçe ders kitapları dil gelişimini ne oranda desteklemektedir. Cito Eğitim: Kuram ve Uygulama, 2, 53-64.

Wang, S., \& Wang, H. (2011). Teaching higher order thinking in the introductory MIS course: A model-directed approach. Journal of Education for Business, 86(4), 208213. 


\title{
Investigation of Activities in Turkish Textbooks in Terms of Thinking Skills \\ Emel-BAYRAK ÖZMUTLU*, Pınar-KANIK UYSAL ${ }^{* *}$
}

- Received: 30.05.2020• Accepted: 19.01.2021 • Online First: 08.04.2021

\begin{abstract}
In this research, the aim was to investigate the distribution of activities included in Turkish textbooks in order to develop thinking skills and the aspects of thinking skills included in these activities. The research used the qualitative research method of document investigation. The scope of the study comprised a total of 3,452 activities included in 8 Turkish textbooks that could be accessed electronically through the EBA program and were published in 2018. The data analysis process in the research used the repeated reading, coding and continuous comparison methods. Research findings show that activities included in Turkish textbooks aimed to develop 21 different thinking skills. The thinking skill targeted most for development in Turkish textbooks was recall. Analysis, interrogation, comparison, discussion, creative writing, problem solving and assessment thinking skills were observed at low rates.
\end{abstract}

Key words: Language skills, thinking skills, upper-level thinking skills, Turkish textbooks

\section{Cited:}

Bayrak Özmutlu, E. \& Kanık Uysal, P. (2021). Investigation of activities in turkish textbooks in terms of thinking skills. Pamukkale University Journal of Education, 52, 518-543.doi: 10.9779/pauefd.745469

\footnotetext{
* Assistant Professor, Ordu University, ORCID:https://orcid.org/0000-0002-1222-3557, emelozmutlu@odu.edu.tr.

** Assistant Professor, Ordu Unversity, ORCID:https://orcid.org/0000-0003-1208-9535, pinarkanikuysal@odu.edu.tr.
} 


\section{Introduction}

In the twenty-first century, called the age of information, being informed is not sufficient alone. The progressively more complicated life makes it mandatory to transform information into skills and has increased the need for individuals with developed skills (Mutluer, 2013). These skills may be listed as critical and creative thinking, especially, effective communication, ability to recommend solutions to problems, ability to research, to make correct decisions, use information technologies and take initiative (Durukan \& Demir, 2017). Individuals with these skills may produce creative solutions using correct strategies when faced with daily life problems and may share these by generalizing (Güneş, 2012). These skills, called upper level thinking skills, guide students within the conditions they face in different stages of life and undertake important roles in the learning process.

The expectation that individuals will need to use upper-level thinking skills in social life and development and conversion of these skills into forms that will be needed in the future (Söylemez, 2018) shapes decisions made within educational policies. This is because education is a process shaped in line with the expectations of individuals and society. It is possible to see the most serious reflection of this effect in the curriculum which entered operation since 2005. The understanding of upper-level thinking skills as an integral part of the curriculum and development within the framework of opportunities within the discipline began to be applied throughout the whole curriculum from this year. The adopted understanding accepted content as a tool for students to acquire upper-level thinking skills (Swartz \& Perkins, 2016). The aim of this process is that while students are busy with content, undertaking a mediating role in terms of development of thinking skills, they use content knowledge in a meaningful way (Fogarty \& McTighe, 1993). In addition to the curriculum, it is possible to assess the academic and political studies completed within the scope of $21^{\text {st }}$ century skills and the Turkish Qualifications Framework in our country within this scope.

Social transformation, affecting decisions and implementations in the teaching and learning process, causes serious transformations to occur in the structure and functioning of textbooks. With the change in understanding experienced with the adopted teaching-learning approach, textbooks each become a teaching tool contributing to the student's configuration process for knowledge, directing their thinking, assisting in acquiring a critical viewpoint and assessments from multiple perspectives (Ocak \& Dai, 2010). From this aspect, Turkish 
textbooks should include activities that will reveal student's previous learning in accordance with the curriculum, prepare them for later learning and ensure they can develop relationships between the text and daily life and develop basic language skills. Additionally, activities should be included in textbooks which develop the basic skills included in the Turkish curriculum (Erdoğan, 2014). Raising students to be individuals who will adjust to conditions of a globalizing world and produce solutions to all types of problems should be among the primary aims of textbooks (Ekinci, Çelikpazu, \& Aktaş 2011).

Textbooks are the most basic material in the teaching-learning process as they are the reference prepared based on the curriculum (Büyükalan \& Y1ldırım, 2019). In Turkish education, the most easily accessible and functional material appears to be textbooks (Karadağ \& Tekercioğlu, 2019). In planned education, textbooks guide what students learn and what teachers teach. In Turkish teaching, teachers are known to primarily use textbooks among use of tools and materials (Özbay, 2003). Textbooks play an important role in students acquiring basic language skills during Turkish lessons, especially, because most language skills in Turkish lessons are acquired by students through texts included in the textbooks and activities related to these texts (Erdoğan, 2014).

As mentioned above, textbooks are very important in terms of the quality of the teaching-learning process. From this aspect, it appears many studies have been completed about Turkish textbooks in this field of educational sciences. Recent research about this topic has investigated teacher opinions about textbooks (Arslan \& Engin, 2019; Sügüumlü, Mutlu, \& Çinpolat, 2019); adequacy for PISA reading skills (Benzer, 2019); texts (Çalışkan, 2016); linguistic skills (Çarkıt, 2019); theme assessment and questions under texts (Çeçen \& Kurnaz, 2015; Eroğlu \& Kuzu, 2014; Sarar-Kuzu, 2013; Savaşkan, 2016); activities (Çevik \& Güneş, 2017; Karadağ, 2019; Tosunoğlu \& Demir, 2014; Ulum \& Taşkaya, 2019); level of meeting critical thinking skills (Demir \& Baş, 2019); interdisciplinary approach (Demir, 2018); reading acquirements (Deniz, Tarakçı, \& Karagöl, 2019); listening/watching acquirements (Dolunay \& Savaş, 2016; Özkanal \& Bayrak, 2016); 21 ${ }^{\text {st }}$ century skills (Gültekin, 2019); constructivist approach (Küçükaydın \& İşcan, 2017); basic skills in the curriculum (Kurudayığlu \& Soysal, 2019; Temizkan, 2014); and curriculum acquirements (Uçgun, 2018). However, there is no research encountered in the relevant literature which investigates Turkish textbooks based on the thinking skills targeted for development by activities in the textbooks. This investigation makes it possible to assess the quality of textbooks in relation to ensuring development of thinking skills. This research investigates 
activities in textbooks based on the scope they deal with. Additionally, there is no research encountered which deals with the study group with a broad understanding from $1^{\text {st }}$ grade to $8^{\text {th }}$ grade. Considering the need for Turkish textbooks to be developed within an appropriate understanding for all stages of teaching, it is considered important to investigate textbooks on the basis of a large range of class levels. As a result, this study included investigation of activities included in Turkish textbooks used at both primary school and secondary school levels.

This study aimed to reveal the quality of textbooks in relation to development of thinking skills. The most accurate way to reveal the quality of textbooks in terms of development of upper level thinking skills is to complete analysis on the basis of thinking skills targeted for development in every activity. Due to this analysis, it will be possible to see what thinking skills students will develop after interacting with the textbooks and the proportions of skills at upper level and at basic level. In the research, analysis based on the scope that thinking skills are dealt with will assess the rate to which opportunities related to thinking skills are used accurately and effectively. It is thought that this analysis in terms of thinking skills in Turkish textbooks will contribute to the field of textbook investigation and Turkish education in terms of forming an assessment criterion for textbooks. In this research aiming to sought answers to the following questions.

1. What is the distribution of thinking skills targeted for development in activities in Turkish textbooks at primary and secondary school level?

2. What aspect is the focus for thinking skills targeted for development in activities in Turkish textbooks at primary and secondary school level?

\section{Method}

This research aims, an investigation needed to be carried out on activities included in textbooks in the scope of the study. As a result, the research adopted the document investigation method, one of the qualitative research methods. According to Scott and Marshall (2015), document investigation uses individual or official documents as research material. In this research, a total of 8 books used in Turkish lessons which began to be used in 2018 and were accessed digitally on the EBA platform were investigated and analyzed. From this aspect, it was considered appropriate to use the document investigation method in the research. 


\section{Scope of the Study}

In this research criteria sampling was used, one of the targeted sampling types. Criteria sampling is defined as selection of all cases abiding by certain criteria (Patton, 2014). Selection of the research sample used the criteria of textbooks used for primary and secondary school Turkish lessons in the 2018-2019 educational year and being digitally accessible on the EBA platform. The study group in the research comprised 8 Turkish textbooks which entered use in 2018 and were open for access in electronic form on the EBA platform. Information about books comprising the study group in the research can be seen in Table 1.

Table 1. Distribution of Teaching Level for Activities Investigated in the Research

\begin{tabular}{lcc}
\hline Level & $\begin{array}{c}\text { Number of Activities } \\
\text { Investigated }\end{array}$ & Publisher \\
\hline 1st grade & 168 & Millî Eğitim Yayınevi \\
2nd grade & 337 & Koza Yayıncılık \\
3rd grade & 386 & Millî Eğitim Yayınevi \\
4th grade & 508 & Millî Eğitim Yayınevi \\
5th grade & 595 & Anıttepe Yayıncılık \\
6th grade & 447 & Millî Eğitim Yayınevi \\
7th grade & 552 & Millî Eğitim Yayınevi \\
8th grade & 459 & Millî Eğitim Yayınevi \\
\hline Total & 3,452 & \\
\hline
\end{tabular}

\section{Analysis of Data}

The data analysis process in the research used repeated reading, coding and continuous comparison methods to follow a detailed analysis process. In the analysis process for the research, primary and secondary school Turkish textbooks included in the scope of the study 
were uploaded to the Max QDA program. As a result of repeated reading, decisions were made about which thinking skill or skills were targeted for development in activities included in the textbooks. When deciding which thinking skills were targeted for development in activities, the question of which thinking skill could be developed during the process of a student completing these activities was asked. The research interrogated each activity with the questions "what mental process is the student expected to perform based on the linguistic stimuli read, heard or watched during the activity?" In this process, thinking skill codes and explanations developed by Bayrak-Özmutlu (2020) were used. Within the scope of the research, the 12 thinking skills based on the research by Bayrak-Özmutlu (2020) are shown in Table 2. The remaining 9 skills apart from these codes and explanations were identified and coded by the researchers during the analysis. Explanations of thinking skills identified by the researchers are given in Table 3. In the analysis process, thinking skills targeted for development were determined and written in boxes in a two-column table beside the acquirements. This process was applied to all 3,452 activities and assessment questions were not included in analysis until the end. Activities classified on the basis of the thinking skill targeted for development had a separate electronic document created for each thinking skill. Twenty-three different documents were created for the 21 thinking skills targeted for development in Turkish textbooks. In this way, it was possible to see all activities targeting development of the same thinking skill one after the other. In this process, activities classified based on thinking skills were read repeatedly and consistency of classification was checked. After checks for consistency between codes, acquirements on the table were classified based on classes and levels. The distribution of thinking skills according to grade and level was summarized using descriptive statistics. To answer the second subproblem in the research, activities aiming to develop the same thinking skill were interrogated with the question "in ... activity, which aspect of ... thinking skill is the focus?" Within this scope, the aim was to see which aspects of activity-based thinking skills were the focus and which were excluded. At the same time, it made it possible to see the scope of the thinking skills determined during the analysis process. Each activity investigated in this stage of the analysis was coded based on the question above. For class clusters according to codes for acquirements based on the aspect of the thinking skill used in the textbook, the continuous comparison method was applied with necessary combination and separation processes performed. After repeated reading, the process continued until the point where the categories stopped varying. Explanations about the analysis process used and the determined thinking skills (categoric structures) are given below. 
Table 2. Thinking Skills and Definitions Used in the Analysis

Thinking Skill Definition

Recall

Students' mental recall of previously-learned knowledge in line with directives and verbal or written expression

Making Inferences Students' creating personal meaning with content that is read, heard/watched, completing all mental functions during this process and combining with background information associated with that content (see. Keene and Zimmermann, 1997)

Differentiation

Prediction

Applying Rules

Evaluation

Meaning-Based

Construction

Analysis

Problem-Solving

Interrogation
Students noticing (finding, determining) the desired element/feature among linguistic stimuli read, heard or watched and making the appropriate reaction to this element

Students making predictions based on linguistic stimuli that are read, heard/watched

Students using functional information in the linguistic skills area in accordance with rules

Students dealing with meaning, importance, quality and a range of quantitative criteria for linguistic stimuli which are read, heard or watched and written or verbal expression of their judgements

Students' written or verbal expression of configured meaning in accordance with directives

Students separation of linguistic stimuli read, heard/watched into between these elements/basic parts

Students' development of solution/s to problems expressed as linguistic stimuli which are read, heard/watched

Students' creation of questions related to the meaning, validity and reliability of linguistic stimuli which are read, heard/watched and elements/basic parts or stages and understanding the relationships 
participation in discussion within this scope

Conversion Students' conversion of written, visual, verbal and movement-based stimuli that are read, heard/watched into others in accordance with directives

Comparison Students investigation to reveal similar or different aspects in terms of form/meaning of linguistic stimuli which are read, heard/watched

Table 3. Thinking Skills and Definitions Used in the Analysis

Thinking Skill Definition

Matching

Visual Reading

Forming Cause-

Outcome

Relationships

Creative Writing

Design

Self-Assessment
Students' matching features between read, heard/watched stimuli by making connections and interest based on commonalities and similarities in line with directives

Students' ability to understand, interpret elements apart from written text like pictures, photographs, posters, symbols, shapes, marks, maps, tables, graphs, caricatures, etc. and express in writing and/or verbally

Student's creating cause and outcome-based relationships between past events that they heard, watched or read or awareness of these relationships and written or verbal expression of these

Students' written expression of feelings, thoughts, observations and dreams without information purposes through fiction or non-fictional routes

Students' mental imagining and shaping of material or linguistic product serving a certain purpose in line with directives and written or verbal expression of this mental creation

Students' written or verbal expression of judgements about their performance based on language skills dealing with a range of criteria 
Accessing

Information Sources

Interpretation

Discussion
Students' accessing secondary sources related to the topic in the directives and written, verbal or visual expression of this information

Students' explanations in relation to the meaning of linguistic elements like adages, proverbs, idioms, sayings, phrases, metaphors, and verses that they read, heard/watched

Students' ability to produce ideas based on situations, provisions, conditions, problems, causes and outcomes of possibilities open to debate and written or verbal expression of these ideas.

\footnotetext{
After completing the analysis process, two researchers met and the intercoder compatibility coefficient was calculated. As a result of calculations, it was determined the intercoder compatibility coefficient was $97 \%$. All activities coded differently by the two researchers were investigated. In this process, notes and explanations made by researchers during the analysis process related to codes were investigated. This process was repeated for each activity coded differently by the two researchers. Common assessments continued until there were no incompatible codes remaining.
}

\section{Validity and Reliability Studies}

In this research adopting the qualitative research method, validity and reliability studies were completed as follows. One of the validity and reliability studies used for qualitative research of persuasiveness means the accuracy and persuasiveness of the collected data (Güler, Halıcıoğlu, \& Taşgın, 2014). In the research, textbooks used in state schools in Turkey in 2018-2019 and with digital access on the EBA platform were investigated. Data analyzed in the scope of the research were taken in the form published in the textbooks. From this aspect, it can be said that data investigated in the research abided by the persuasiveness requirement. Another way to ensure persuasiveness in qualitative research is to explain in detail the group numbers and features, how they were chosen, data collection tools used in the research and analysis techniques (Creswell \& Miller, 2000). Within the scope of this requirement, this information is explained in detail under the method heading. Intercoder reliability is one of the reliability requirements in qualitative research. Within the scope of this requirement, analysis was independently completed by two researchers. One of the researchers is an expert in educational programs and teaching and the other is an expert in the field of Turkish education. Calculation of the reliability in the research used the 
E. Bayrak Özmutlu, \& P. Kanık Uysal / Pamukkale University Journal of Education, 52, 518-543, 2021

reliability formula of Reliability $=$ Consensus / (Consensus + Divergence) $\times 100$ proposed by Miles and Huberman (2016). As a result of calculations, reliability was determined to be 97\%. During data analysis, each researcher took notes related to why each activity was coded with the particular thinking skill. The analysis process for activities with no intercoder compatibility was based on assessment of explanations based on these notes and literature investigations. Assessments continued until consensus was reached for coding of each activity. Additionally, codes are stated openly and clearly during presentation of findings and supported with direct citations in an attempt to increase the validity and reliability of the study.

\section{Findings}

\section{Findings related to First Subproblem in the Research}

The first problem in the research sought the answer to the question of "what is the distribution of thinking skills targeted for development in activities in Turkish textbooks according to class level?" The distribution of thinking skills targeted for development in activities in Turkish textbooks according to grade is shown in Table 4.

Table 4. Distribution on the Basis of Thinking Skills Targeted for Development in Activities included in Turkish Textbooks

\begin{tabular}{|c|c|c|c|c|c|c|c|c|c|c|}
\hline \multirow[t]{2}{*}{ Thinking Skills } & \multicolumn{2}{|c|}{ 1st grade } & \multicolumn{2}{|c|}{ 2nd grade } & \multicolumn{2}{|c|}{ 3rd grade } & \multicolumn{2}{|c|}{ 4th grade } & \multicolumn{2}{|c|}{ Mean } \\
\hline & $\mathrm{f}$ & $\%$ & $\mathrm{f}$ & $\%$ & $\mathrm{f}$ & $\%$ & $\mathrm{f}$ & $\%$ & $\mathrm{f}$ & $\%$ \\
\hline Meaning-Based & 2 & 1,19 & 10 & 2,97 & 2 & 0,52 & 2 & 0,39 & 16 & 1,14 \\
\hline \multicolumn{11}{|l|}{ Construction } \\
\hline Differentiation & 7 & 4,17 & 19 & 5,64 & 9 & 2,33 & 12 & 2,36 & 47 & 3,36 \\
\hline Accessing & 0 & 0,00 & 8 & 2,37 & 0 & 0,00 & 21 & 4,14 & 29 & 2,07 \\
\hline \multicolumn{11}{|l|}{ Information Sources } \\
\hline Making Inferences & 10 & 5,95 & 31 & 9,20 & 35 & 9,06 & 50 & 9,86 & 126 & 9 \\
\hline Analysis & 0 & 0,00 & 1 & 0,30 & 4 & 1,04 & 2 & 0,39 & 7 & 0,5 \\
\hline Evaluation & 5 & 2,98 & 0 & 0,00 & 5 & 1,30 & 2 & 0,39 & 12 & 0,86 \\
\hline
\end{tabular}




$\begin{array}{lrlllllllll}\text { Conversion } & 0 & 0,00 & 0 & 0,00 & 1 & 0,26 & 4 & 0,79 & 5 & 0,36 \\ \text { Matching } & 18 & 10,71 & 37 & 10,98 & 16 & 4.15 & 29 & 5,71 & 100 & 7,15\end{array}$

$\begin{array}{lllllllllll}\text { Visual/Graph/Table } & 7 & 4,17 & 9 & 2,67 & 8 & 2,07 & 21 & 4,13 & 45 & 3,22\end{array}$

Reading

Recall

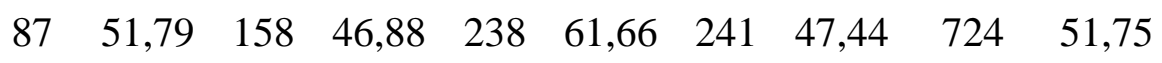

Forming Cause-

$\begin{array}{lllll}4 & 2,38 & 10 & 2,97 & 6\end{array}$

$1,55 \quad 17 \quad 3,35$

$37 \quad 2,64$

Outcome

Relationships

\begin{tabular}{|c|c|c|c|c|c|c|c|c|c|c|}
\hline Comparison & 1 & 0,60 & 3 & 0,89 & 0 & 0,00 & 8 & 1,57 & 12 & 0,86 \\
\hline Applying Rules & 14 & 8,33 & 12 & 3,56 & 17 & 4,40 & 31 & 6,10 & 74 & 5,29 \\
\hline Self-Assessment & 1 & 0,60 & 17 & 5,04 & 0 & 0,00 & 0 & 0,00 & 18 & 1,29 \\
\hline Problem-Solving & 2 & 1,19 & 3 & 0,89 & 1 & 0,26 & 10 & 1,97 & 16 & 1,14 \\
\hline Interrogation & 0 & 0,00 & 0 & 0,00 & 1 & 0,26 & 7 & 1,38 & 8 & 0,57 \\
\hline Prediction & 8 & 4,76 & 16 & 4,75 & 32 & 8,29 & 39 & 7,68 & 95 & 6,8 \\
\hline Design & 1 & 0,60 & 0 & 0,00 & 2 & 0,52 & 3 & 0,59 & 6 & 0,43 \\
\hline Discussion & 0 & 0,00 & 0 & 0,00 & 1 & 0,26 & 2 & 0,39 & 3 & 0,21 \\
\hline Creative Writing & 1 & 0,60 & 3 & 0,89 & 8 & 2,07 & 5 & 0,98 & 17 & 1,22 \\
\hline Interpretation & 0 & 0,00 & 0 & 0,00 & 0 & 0,00 & 2 & 0,39 & 2 & 0,14 \\
\hline Total & 168 & 100 & 337 & 100 & 386 & 100 & 508 & 100 & 1.399 & 100 \\
\hline
\end{tabular}

\begin{tabular}{llllllllllll}
\hline Thinking Skills & 5th grade & 6th grade & 7th grade & 8th grade & & \multicolumn{2}{c}{ Mean } \\
\cline { 2 - 9 } & $\mathrm{f}$ & $\%$ & $\mathrm{f}$ & $\%$ & $\mathrm{f}$ & $\%$ & $\mathrm{f}$ & $\%$ & $\mathrm{f}$ & $\%$ \\
\hline
\end{tabular}


E. Bayrak Özmutlu, \& P. Kanık Uysal / Pamukkale University Journal of Education, 52, 518-543, 2021

Meaning-Based

325,38

$32 \quad 6,71$

22

$3,99 \quad 30$

$6,54 \quad 116 \quad 5,57$

Construction

Differentiation

Accessing

Information Sources

Making Inferences

Analysis

Evaluation

Conversion

Matching

Visual/Graph/Table

Reading

Recall

Comparison

Applying Rules

Forming Cause-

Outcome

Relationships

Self-Assessment

Problem-Solving

Interrogation

Design

Prediction $\begin{array}{llllllllll}31 & 5,21 & 26 & 5,45 & 62 & 11,23 & 45 & 9,79 & 164 & 7,87\end{array}$

$\begin{array}{llllllllll}25 & 4,20 & 13 & 2,73 & 14 & 2,54 & 6 & 1,31 & 58 & 2,78\end{array}$

$\begin{array}{llllllllll}51 & 8,57 & 25 & 5,24 & 59 & 10,69 & 43 & 9,37 & 178 & 8,55\end{array}$

$\begin{array}{llllllllll}12 & 2,02 & 8 & 1,68 & 8 & 1,45 & 6 & 1,31 & 34 & 1,63\end{array}$

$\begin{array}{llllllllll}16 & 2,69 & 4 & 0,84 & 9 & 1,63 & 8 & 1,74 & 37 & 1,78\end{array}$

$\begin{array}{llllllllll}7 & 1,18 & 9 & 1,89 & 5 & 0,91 & 4 & 0,87 & 25 & 1,2\end{array}$

$\begin{array}{llllllllll}38 & 6,39 & 51 & 10,69 & 22 & 3,99 & 35 & 7,63 & 146 & 7,01\end{array}$

$\begin{array}{llllllllll}15 & 2,52 & 18 & 3,77 & 9 & 1,63 & 10 & 2,18 & 52 & 2,45\end{array}$

$218 \quad 36,64 \quad 160 \quad 33,53 \quad 189 \quad 34,22 \quad 174 \quad 37,91 \quad 741 \quad 35,58$

$\begin{array}{llllllllll}6 & 1,01 & 6 & 1,26 & 16 & 2,90 & 4 & 0,87 & 32 & 1,54\end{array}$

$\begin{array}{llllllllll}37 & 6,22 & 18 & 3,77 & 19 & 3,44 & 11 & 2,40 & 85 & 4,09\end{array}$

$\begin{array}{llllllllll}34 & 5,70 & 28 & 5,87 & 31 & 5,62 & 22 & 4,79 & 115 & 5,56\end{array}$

$\begin{array}{llllllllll}5 & 0,84 & 0 & 0,00 & 4 & 0,72 & 6 & 1,31 & 15 & 0,72\end{array}$

$\begin{array}{llllllllll}4 & 0,67 & 0 & 0,00 & 8 & 1,45 & 4 & 0,87 & 16 & 0,77\end{array}$

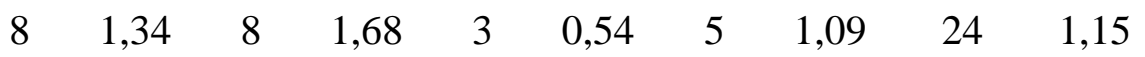

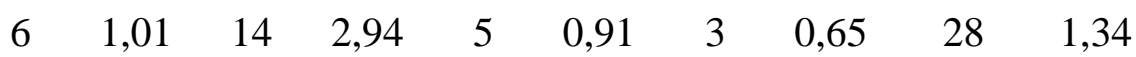

$\begin{array}{llllllllll}23 & 3,87 & 16 & 3,35 & 34 & 6,16 & 22 & 4,79 & 95 & 4,56\end{array}$ 


\begin{tabular}{lcccccccccc} 
Discussion & 7 & 1,18 & 1 & 0,21 & 6 & 1,09 & 0 & 0,00 & 14 & 0,67 \\
Creative Writing & 16 & 2,69 & 32 & 6,71 & 19 & 3,44 & 11 & 2,40 & 78 & 3,74 \\
Interpretation & 4 & 0,67 & 8 & 1,68 & 8 & 1,45 & 10 & 2,18 & 30 & 1,44 \\
\hline Total & 595 & 100 & 477 & 100 & 552 & 100 & 459 & 100 & 2.083 & 100 \\
& & & & & & & & & & \\
\hline
\end{tabular}

The distribution based on thinking skills targeted for development in activities in Turkish textbooks is shown in Table 4. It appears textbooks aimed to develop 21 different thinking skills. In this way, 15 thinking skills were included for $1^{\text {st }}$ and $2^{\text {nd }}$ grade, 17 for $3^{\text {rd }}$ grade, 20 for $4^{\text {th }}$ grade, $215^{\text {th }}$ grade, 19 for $6^{\text {th }}$ grade, 21 for $7^{\text {th }}$ grade and 20 for $8^{\text {th }}$ grade.

When mean values are investigated for distribution of activities included in primary school Turkish textbooks based on thinking skills, activities in the top three places involved skills related to recall, explanation, making inferences and matching. The investigation found the thinking skills of analysis, interrogation, conversion, comparison, design, evaluation and discussion had mean values below 1\%. Additionally, the creative writing, problem-solving and self-assessment thinking skills had mean value below $2 \%$. The research findings show that all upper level thinking skills included in primary school Turkish textbooks are below $1 \%$ and $2 \%$.

When mean values according to distribution of activities in secondary school Turkish textbooks based on thinking skills are investigated, activities in the top three places were observed to involve thinking skills of recall, making inferences and differentiation. The investigation found the mean values for problem-solving, self-assessment and discussion thinking skills were below $1 \%$. Additionally, analysis, interrogation, conversion, comparison, evaluation and design thinking skills had mean values below $2 \%$. The research findings show that all thinking skills with values below $1 \%$ and $2 \%$ in secondary school Turkish textbooks were upper level thinking skills.

The distribution of activities in Turkish textbooks on the basis of grade shows that there was no proportional distribution of thinking skills based on grade level. The mean values for thinking skills targeted for development in activities in the investigated textbooks do not have parallel appearance with the classes. For example, the number of activities targeting development of the problem-solving skill, which may be assessed within the scope of upper level thinking skills, was 2 for $1^{\text {st }}$ grade in primary school, while there was no 
E. Bayrak Özmutlu, \& P. Kanık Uysal / Pamukkale University Journal of Education, 52, 518-543, 2021

activity targeting development of problem-solving skills in $6^{\text {th }}$ grade. Similarly, when creative thinking skills are examined, it appears that as class levels rise from $6^{\text {th }}, 7^{\text {th }}$ and $8^{\text {th }}$ grade, the number of activities targeting development of this thinking skill reduced.

It appears that more than half of activities in the investigated textbooks targeted development of three thinking skills. These thinking skills are recall, making inferences and matching. Nearly all of the making inferences thinking skill activities in textbooks were configured in the same way in each grade as reading comprehension studies about the finding the main thought/emotion and topic.

\section{Findings Related to the Second Subproblem in the Research}

The second subproblem in the research sought the answer to the question "what aspects of thinking skills are targeted for development in Turkish textbooks?" Below, the aspects of the 21 thinking skills targeted for development in activities in Turkish textbooks are investigated along with activity examples.

There were five areas of use for the recall thinking skill in activities included in Turkish textbooks. These were recall of content that was read, heard or watched; answering questions about recall levels of content that was read, heard or watched; and recall of information about concepts, cases, events and people, expression of feelings, thoughts, dreams, intuition, desires, experience and opinions of imagined or reality-based situations, cases, events and people, writing while looking at the text; and reading the text from memory.

There were five areas of use for the making inferences thinking skill in activities included in Turkish textbooks. These were determining the title, main idea, main thought, main emotion, theme and topic of content that was read, heard or watched; making inferences based on imagined or possible real situations; making inferences about the features of a character that was read, heard or watched; making inferences about the contribution of a word or phrase (saying, proverb), rhetoric and transition and connection phrases in content that is heard, watched and read; and making inferences about the reasons for language rules (spelling, punctuation).

There were four areas of use for matching thinking skills in activities in Turkish textbooks. These were matching concepts with meanings; matching areas of use for punctuation with examples; matching synonyms and antonyms; and matching pictures with meanings. There were two areas of use for the differentiation thinking skill in activities 
included in Turkish textbooks. These were differentiation of personality traits expressed in content that was read, heard or watched and differentiating the desired feature in terms of type, structure, form and semantic traits.

There were four areas of use for the prediction thinking skill included in Turkish textbooks. These were making predictions about the text based on the picture and title for a text that will be heard/read; predicting the continuation of a heard/read text; making predictions about the situations expressed in texts that are heard, watched or read; and predicting the meaning of words, phrases, sayings and proverbs with unknown meaning.

There were three areas of use for the applying rules thinking skill in activities included in Turkish textbooks. These were forming sentences using words and rules with the desired features (punctuation, sound events); explaining a language rule with examples and requesting the same rule be followed; and requesting correction of errors in form or meaning in sentences as explained in the directives.

There were three areas of use for the visual reading thinking skill in activities included in Turkish textbooks. These were explaining and interpreting visuals; answering questions about visuals; and writing a story/dialogue/joke using more than one visual image.

There were two areas of use for the forming a cause-outcome thinking skill in activities included in Turkish textbooks. These were reasoning in relation to the causes of what was read, heard or watched and forming cause-outcome relationships between two different situations in what was read, heard or watched.

There were five areas of use for the creative writing thinking skill within activities included in Turkish textbooks. These were explaining observations about an imaginary situation; writing a poem, story, fairytale, fable, letter or telephone interview based on the given topic; setting up a narrated event in a different form; completing stories, fairy tales, jokes; and writing a slogan.

There were two areas of use for the evaluating thinking skill in activities included in Turkish textbooks. These were evaluating text and visuals based on a range of criteria and evaluating events/situations/personalities represented in texts that are read, heard or watched based on directives. There were five areas of use for the design thinking skill in activities included in Turkish textbooks. These were product/project design related to solving a problem, design of toys/playgrounds, graphic design, signature design, design of speeches and writing processes and design of tools and user guides. 
There was one area of use for the self-assessment thinking skill in activities included in Turkish textbooks and this was to assess reading, writing and speaking skills by comparison with a range of criteria. There were three areas of use for meaning-based construction thinking skills in activities included in Turkish textbooks. These include preparing and making a speech in accordance with directives given in the context of a certain topic; writing an informative text within the context of a certain topic; and summarizing content that is read, heard or watched.

There was one area of use for the accessing information sources thinking skill in activities included in Turkish textbooks and this was accessing primary or secondary information sources with assistance or independently about a given topic. There were four areas of use for the analysis thinking skill in activities included in Turkish textbooks. These were separating a job into process directives; differentiating the elements of a written text; analyzing the living organisms; and differentiating elements of a sentence.

There are two areas of use for the problem-solving thinking skill in activities included in Turkish textbooks. These were noticing, identifying and solving problems experienced in surroundings; thinking logically about solutions to real-life problems; and thinking logically about solutions to social and emotional problems of imagined protagonists.

There were two areas of use for the interrogation thinking skill in activities included in Turkish textbooks. These were creating questions related to what was read, heard or watched and interrogating the consistency of content that was read, heard or watched. There were four areas of use for conversion thinking skills in activities included in Turkish textbooks. These were re-enacting text that was read, heard or watched; spatial thinking; conversion from one type to another; and creating graphs.

There were four areas of use for the comparison thinking skill in activities included in Turkish textbooks. These were comparing the character traits of protagonists mentioned in a text that was read, heard or watched; comparing the physical features of elements included in a text that was read, heard or watched; comparing texts that were read, heard or watched in terms of topic, type and form; and comparing two situations based on reality or possible fictions.

There was one area of use for the interpretation thinking skill in activities included in Turkish textbooks and this was making explanations related to the meaning of elements like 
adages, proverbs, idioms, phrases, metaphors, and verses. There was one area of use for the discussion thinking skill in activities included in Turkish textbooks and this was producing possible cause and outcomes of situations open to debate, conditions, provisions, problems and probabilities and expressing these ideas in writing or verbally.

\section{Discussion and Conclusion}

This research aimed to determine the status of linguistic skill activities included in textbooks for development of thinking skills. Within this scope, a total of 3.452 activities included in Turkish textbooks from $1^{\text {st }}-8^{\text {th }}$ grade were investigated. Activities were analyzed based on thinking skills that were targeted for development. In this way, it may be possible to see the thinking skills with potential for development by textbooks among students from $1^{\text {st }}$ grade to $8^{\text {th }}$ grade. With this, it will be possible to see which thinking skills dominate and which are neglected, rates for lower level and upper level thinking skills and comparatively view the distribution based on classes. Data presented in the research make it possible to interrogate the potential in relation to development of thinking skills with linguistic skills and the rate to which textbooks are used accurately and effectively. The research observed that 21 different thinking skills were targeted for development in Turkish textbooks. The activities in the top three places for primary and secondary school levels involved recall, explanation and making inferences thinking skills.

The research found that nearly all upper level thinking skills had rates below $1 \%$ and $2 \%$ in Turkish textbooks at primary and secondary school level. Much research about this topic in the literature supports these findings. For example, research by Çeçen and Kurnaz (2015) determined that the rate of questions including the assessment and creation stages in Turkish textbooks was $1 \%$. Similarly, Şengül (2005) concluded that moving from lower level thinking skills toward upper level ones, the number of questions largely reduced in research about text-based questions. Sarar-Kuzu (2013) stated that Turkish textbooks had low rates of questions involving upper level mental processes in questions below text. Another research mentioned imbalance in textbooks toward the lower level cognitive skill stages of recall, comprehension and application (Dolunay \& Savaş, 2016). Küçükaydın and İşcan (2017) concluded that learning through activities in Turkish student workbooks was about acquiring basic level skills, while Yağmur (2009) stated that Turkish textbooks did not develop the upper level cognitive skills of students. Çevik and Güneş (2017) revealed that linguistic knowledge activities involved automatic repetition, some were prepared as multiple choice, sentence translation, identification, finding synonyms, etc. in research about 
activities included in Turkish textbooks. Though these types of activities do not contribute much to rapid memorization and language learning, they were stated to be commonly used (Çevik \& Güneş, 2017).

If findings related to thinking skills are examined in more detail, it should be stated that activities directing students towards research and investigation in textbooks include question sentences ending with the directive "research this topic". Activities in this form do not include any direction or staging about the steps and requirements of research and investigation processes. Additionally, there was no structured activity to develop this skill within an intertwined understanding based on themes. Activities contain no direction about which resources students can collect information from, what interrogation should be performed or precautions taken about the validity and reliability of this information, or about how this information should be recorded and reported. Additionally, the number of activities directing students towards research and investigation have very low percentages $(2.1 \%$ in primary school, $2.78 \%$ in secondary school).

It appears the rate of interrogation and problem-solving thinking skills which can be assessed within the scope of critical thinking was below $1 \%$ in the research. Benzer (2019) found similar findings and concluded that it was thought-provoking that in spite of 14 years since the entry into use of the 2006 Turkish Lesson Curriculum in the Turkish education system, textbooks did not use skills like critical thinking. Dolunay and Savaş (2016) identified that there were no activities to develop the critical thinking skills of students in workbooks for $6^{\text {th }}, 7^{\text {th }}$ and $8^{\text {th }}$ grade Turkish lessons. Another research investigating the opinions of teachers about textbooks (Gün, 2012) revealed that $65 \%$ of teachers thought reading activities were insufficient in terms of development of critical and creative thinking among students. Research by Temizkan (2014) interpreted the very low rates of inclusion for problem-solving skills in texts in Turkish textbooks as thought-provoking and stated that critical thinking displayed a very irregular distribution in textbooks. In another study about texts in Turkish textbooks, Başoğlu and Mutlu (2012) stated that most texts included in $7^{\text {th }}$ and $8^{\text {th }}$ grade Turkish textbooks did not encourage students to think, did not stimulate curiosity and were texts presenting prepared information. A similar study completed about the Turkish Lesson Curriculum by Söylemez (2018) made the interpretation that acquirements including low numbers related to critical thinking neglected creative thinking and problem solving. Anxiety about remaining faithful to acquirements and direct efficacy on acquirements when preparing textbooks causes repeated activities to be included in each 
class level and while the class level changed the activity content remained the same. For example, the 'make a prepared speech' acquirement in fifth grade involves a student who has not prepared activities with lower cognitive loads (researching, preparing text, using ways to develop thinking to support thoughts, etc.) is expected to achieve these acquirements in each class level directly, or just make a prepared speech. A study by Karadağ and Tekercioğlu (2019) made similar statements, that Turkish textbooks were prepared with outcome-focused activities without paying attention to cognitive loads.

It appeared that nearly all of the acquirements targeting development of creative thinking skills in the research were about creative writing. Additionally, it is important to state that none of the activities within this scope were specially designed activities to develop the creative thinking skills of students. Most of these activities comprised directives targeting students' ability to complete creative writing work. There was no direction, assessment or information aiming to develop creative thinking skills before or after the activities. From this aspect, there appears to be a deficiency in terms of a systematic development route for the creative thinking skills of students. The rate of activities targeting development of creative thinking skills in the analyzed textbooks was $3.38 \%$ for primary school and $4.28 \%$ for secondary school. Temizkan (2014), who completed an investigation of this topic, stated that Turkish textbooks included very inadequate rates of creative thinking activities. Dolunay and Savaş (2016) found the number of activities in the creative stage among listening activities were very low. Çeçen and Kurnaz (2015) stated the need to include sufficient numbers of questions in the creation stage in Turkish textbooks.

In the research, there appeared not to be a balanced distribution of a range of thinking skills both within themselves and on a grade basis. It is necessary to question whether this situation observed in Turkish textbooks has a scientific basis or not. Dolunay and Savaş (2016) stating similar findings concluded that there was a gap in the cognitive skill stages in the distribution of listening activities. Bayram and Baki (2014) investigated types of intelligence targeted for development in activities and identified that activities did not have proportional distribution in their research. The investigation stated that frequencies were $60.37 \%$ for verbal-linguistic intelligence and $15 \%$ for logic-mathematical intelligence areas (Bayram \& Baki 2014). Similar findings are reflected in research based on acquirements and skills in Turkish textbooks (Bayrak-Özmutlu, 2020; Büyükalan \& Y1ldirım, 2019). 
Another finding related to activities in textbooks is that the activities are of a single type. In addition to nearly half of activities focusing on three thinking skills, similar directives and explanations were present from $1^{\text {st }}$ to $8^{\text {th }}$ grade. For example, nearly all activities related to the making inferences thinking skill comprised activities about finding the topic, main idea/main emotion with the same directives in each class level. Findings by Benzer (2019) were similar, stating that questions in textbooks were not encountered at the level of the most common assessments and in-depth analysis questions on PISA. The same study found that the questions under text in textbooks focused on the level of accessing knowledge and recall of information. Çeçen and Kurnaz (2015) stated that questions were dominantly one type in their thematic assessment of textbooks and interpreted that this did not sufficiently reflect the individual differences noted in the Turkish Lesson Curriculum and understanding of different evaluation methods for measurement. Dağ (2007) identified that activities included in textbooks were uniform, similar to each other and repetitive. Research by Çevik and Güneş (2017) found evaluation was based on a single type as observed for linguistic skill activities in their research. Another finding about the single type of activities belongs to Kılıç, Baki, and Yıldırım (2014). In the research they stated that activities based on verbal-language and logic-mathematic intelligence dominated textbooks and the necessary importance was not given to other areas of intelligence. A study by Coşkun (2013) stated that apart from single-response questions, there was no inclusion of question types where readers had to associate information in different texts at any class level and that activities did not encompass upper level reading skills. Bozkurt, Uzun, and Lee (2015) determined that the most commonly encountered question types in Turkish textbooks were at the level of accessing information-recall. It appears that this information in the relevant literature and the findings obtained in this study overlap.

It is possible to make the following recommendations based on the research findings. It was concluded that low rates of activities in textbooks involve upper level thinking skills. At this point, the importance of the need (Benzer, 2019) to investigate textbooks on the basis of thinking skills targeted for development by the Board of Education is underlined. An important necessity is to provide information about the acquirement related to the activity and which thinking skill is targeted for development at the start of activities in textbooks. The Turkish lesson leads the lessons where critical thinking skills can be best acquired by students (Temizkan, 2014). From this aspect, when developing activities, it is important to note the potential in terms of development of thinking skills in Turkish lessons. Attention 
should be paid to the potential for thinking skill development along with each acquirement and linguistic skill taken as the basis for the activities. Textbooks should be developed within a complementary intertwined common understanding from $1^{\text {st }}$ grade to $8^{\text {th }}$ grade. Each thinking skill should be developed with planned activities based on teaching and learning principles from $1^{\text {st }}$ grade to $8^{\text {th }}$ grade. As upper level thinking skills involve the simultaneous or sequential use of many thinking skills, activities should include necessary directives and information under the preparation, implementation and assessment steps in activities appropriate to the nature of this thinking skill. Awareness should note that upper level thinking skills cannot be developed by just a question directive and textbooks should be evaluated and oriented in this scope during the preparation process. A textbook structured with the correct understanding has significant potential in terms of guiding the teacher about development of upper level thinking skills.

Ethical Approval: Since the scale and questionnaire were not used in this study, permission from the ethics committee was not required.

Conflict of Interest: Authors have no conflict of interest to declare.

Author Contributions: The first author contributed to the study at the stages of determining the problem situation, collecting data and analyzing the data. The second author contributed to the study in determining the scope of the study, determining the problem situation and analyzing the data. On the other hand, all authors contributed to the study during the literature review, discussion and reporting stages. 


\section{References}

Arslan, A., \& Engin, A. O. (2019). 5. sınıf Türkçe dersi öğretim programının öğretmen görüşlerine göre değerlendirilmesi. The Journal of Interdisciplinary Educational Research, 3(5), 19-39.

Başoğlu, N., \& Mutlu, B. (2012). İlköğretim Türkçe ders kitaplarında yer alan metinlerin eleştirel düşünme eğitimine uygunluğu. Kastamonu Education Journal, 20(3), 983998.

Bayrak-Özmutlu, E. (2020). The distribution of the mother tongue curricula learning outcomes based on the thinking skills. Cukurova University Faculty of Education Journal, 49 (1), 185-224.

Bayram, B., \& Baki, Y. (2014). Ortaokul 6. sınıf Türkçe dersi öğretmen kılavuz kitabının çoklu zekâ kuramı açısından değerlendirilmesi. Dil ve Edebiyat Eğitimi Dergisi, (9), 113-147.

Benzer, A. (2019). Türkçe ders kitaplarının PISA okuma yeterlik düzeyleri ile imtihan1. Research in Reading and Writing Instruction, 7(2), 96-109.

Bozkurt, B. Ü., Uzun, G. L., \& Lee, Y. (2015). Korece ve Türkçe ders kitaplarındaki metin sonu sorularının karşılaştırılması: PISA 2009 sonuçlarına dönük bir tartışma. International Journal of Language Academy, 3(9), 295-313.

Büyükalan, F. S., \& Yıldırım, N. (2019). Ortaokul Türkçe dersi öğretim programı kazanımlarının revize edilmiş Bloom Taksonomisine göre analizi. Elementary Education Online, 18(4), 1551-1573.

Creswell, J. W., \& Miller, D. L. (2000). Determining validity in qualitative inquiry. Theory into Practice, 39(3), 124-130.

Coşkun, Y. D. (2013). Türkçe ders kitaplarının PISA sınavı okuma ölçütleri açısından incelenmesi. Mehmet Akif Ersoy University Journal of Education Faculty, 13(26), $22-43$.

Çalışkan, G. (2016). Türkçe dersi öğretim programı ve Türkçe ders kitapları: 5. sınıf Türkçe ders kitabına yönelik bir inceleme. Journal of Mother Tongue Education, 4(2), 200214. 
Çarkıt, C. (2019). 2018 Türkçe dersi öğretim programı çerçevesinde hazırlanan 8. sınıf Türkçe ders kitabının değerlendirilmesi.Electronic Journal of Social Sciences, 18(71), 1368-1376.

Çeçen, M. A., \& Kurnaz, H. (2015). Ortaokul Türkçe dersi öğrenci çalışma kitaplarındaki tema değerlendirme soruları üzerine bir araştırma. Karadeniz Sosyal Bilimler Dergisi, 7(02). https://dergipark.org.tr/tr/pub/ksbd/issue/16219/169872.

Çevik, A., \& Güneş, F. (2017). Türkçe ders kitaplarındaki etkinliklerin incelenmesi. Journal of Mother Tongue Education, 5(2), 272-286.

Dă̆, Ö. (2007). Illköğretim Türkçe dersi programlarına (1981-2005) ĕgitimsel dilbilim açısından eleştirel bir bakış [Unpublished Master Thesis]. Ankara University, Institute of Social Sciences, Ankara.

Demir, H., \& Baş, Ö. (2019). Türkçe ders kitabındaki metinlerin eleştirel düşünme ölçütlerini karşılaması üzerine nitel bir araştırma. Journal of Turkish Literature Culture Education (TLCE), 8(2), 983-1006.

Deniz, K., Tarakcı, R., \& Karagöl, E. (2019). Okuma kazanımları açısından ortaokul türkçe ders kitaplar1. Journal of Mother Tongue Education, 7(3), 688-708.

Dolunay, S. K., \& Savaş, Ö. (2016). Assessing listening activities in secondary school Turkish language textbooks in terms of higher order thinking skills. Journal of Theory and Practice in Education, 12(1), 122-157.

Durukan, E., \& Demir, E. (2017). 6, 7 ve 8. sınıf Türkçe dersi öğrenci çalışma kitaplarındaki etkinliklerin Bloom'un yenilenmiş taksonomisine göre siniflandırılması. International Journal of Turkish Literature Culture Education (TLCE), 6(3), 1619-1629.

Ekinci-Çelikpazu, E., \& Aktaş, E. (2011). MEB 6, 7 ve 8. sınıf Türkçe ders kitaplarında yer alan metinlerin değer iletimi açısından incelenmesi. Turkish Studies, 6(2), 413-424.

Erdoğan, T. (2014). İlkokul 1-4. Sinıflar Türkçe dersi öğrenci çalışma kitaplarındaki etkinliklerin yaratıcı düşünme becerisi açısından incelenmesi. Dicle Üniversitesi Ziya Gökalp Eğitim Fakültesi Dergisi, (23), 25-58.

Eroğlu, D., \& Kuzu, T. S. (2014). Türkçe ders kitaplarındaki dilbilgisi kazanımlarının ve sorularının yenilenmiş Bloom taksonomisine göre değerlendirilmesi. Başkent University Journal of Education, 1(1), 72-80. 
Fogarty, R., \& McTighe, J. (1993). Educating teachers for higher order thinking: The threestory intellect, Theory into Practice, 32, 161-169.

Güler, A., Halıcıoğlu, M.B., \& Taşğın, S. (2013). Sosyal bilimlerde nitel araştırma yöntemleri. Ankara: Seçkin Yayıncılı.

Gültekin, H. (2019). Türkçe dersi öğrenci çalışma kitaplarının 21. yüzyıl becerileri açısından incelenmesi [Unpublished Master Thesis]. Balıkesir University, Institute of Social Sciences, Balıkesir.

Gün, M. (2012). İlköğretim ikinci kademe Türkçe dersi okuma etkinliklerinde karşılaşılan sorunlar. Electronic Turkish Studies, 7(4), 1961-1977.

Güneş, F. (2012). Testlerden etkinliklere Türkçe öğretimi. Dil ve Edebiyat Eğitimi Dergisi, 1(1), 31-42.

Güneş, F. (2017). Türkçe öğretiminde etkinlik yaklaşımı. Journal of Mother Tongue Education, 5(1), 48-64.

Karadağ, Ö. (2019). Aynı sınıf düzeyi için hazırlanan Türkçe ders kitaplarının ortak söz varlığı açısından karşılaştırılması. Journal of Mother Tongue Education, 7(4), 11301140 .

Karadağ, Ö., \& Tekercioğlu H. (2019). Türkçe ders kitaplarındaki bilişsel ve üstbilişsel işlevlere dair bir durum tespiti. Mersin University Journal of the Faculty of Education, 15(3), 628-64.

Kılıç, L. K., Baki, Y., \& Bayram, B. (2014). Ortaokul 8. sınıf Türkçe dersi öğretmen kılavuz kitabındaki etkinliklerin çoklu zekâ kuramı ile örtüşme düzeyi. Journal of Mother Tongue Education, 2(2), 72-89.

Kurudayığlu, M., \& Yaşar, F. Ö. (2014). 6. sınıf Türkçe dersi öğretmen kılavuz kitaplarındaki dinleme metinlerinin dinleme yöntem ve teknikleri açısından incelenmesi. Journal of Mother Tongue Education, 2(2), 1-14.

Kuzu, T. S. (2013). Türkçe ders kitaplarındaki metin altı sorularının yenilenmiş Bloom taksonomisindeki hatırlama ve anlama bilişsel düzeyleri açısından incelenmesi. Cumhuriyet Üniversitesi Edebiyat Fakültesi Sosyal Bilimler Dergisi, 37(1), 58-76. 
Küçükaydın, M. A., \& İşcan, A. (2017). İlköğretim 3. sınıf Türkçe ders kitapları ve öğretmen kılavuz kitabının yapılandırmacı öğrenme yaklaşımına uygunluk düzeyi. Journal of Mother Tongue Education, 5(1), 1-13.

Marzano, R. J. (2001). Designing a new taxonomy of educational learning outcomes. Thousand Oak, CA: Corwin Press, Inc.

Mutluer, C. (2013). Sosyal bilgiler programlarında yer alan beceriler hakkında sosyal bilgiler öğretmen görüşleri (İzmir Menemen Örneği), Turkish Studies, 8(7), 355-362.

Ocak, G., \& Dai, A. (2010). İlköğretim dördüncü sınıf Türkçe ders ve çalışma kitaplarının yapılandırmacı öğrenme anlayışına göre değerlendirilmesi. The Journal of Turkish Social Research, 3, 91-108.

Özbay, M. (2003). Türkçe öğretiminde hedef-araç ilişkisinin ders kitabı örneğinde değerlendirilmesi. Journal of Turkology Research, 13, 59-69.

Özkanal, Ü., \& Bayrak, E. (2016). İlkokul Türkçe çalışma kitaplarındaki dinleme etkinliklerinin zihinsel becerilere göre dağılımı. Journal of Kirsehir Education Faculty, 17(1), 201-220.

Patton, M. Q. (2014). Nitel araştırma ve değerlendirme yöntemleri. (Çev. Ed. M. Bütün ve S. B. Demir). Pegem Akademi Yayınları, Ankara.

Savaşkan, V. (2016). Ortaöğretim 9. sınıf Türk Edebiyatı ders kitaplarındaki metin altı soruları üzerine bir inceleme. Hitit University Journal of Social Sciences Institute, 9(2), 821-836.

Scott, J., \& Marshall, G. (2015). A dictionary of sociology (3 ${ }^{\text {th }}$ ed.). London: Oxford University Press.

Soysal, T., \& Kurudayığlu, M. (2019). Study of ministry of education 9th grade Turkish language and literature coursebook in terms of the skills and capabilities in the 2017 program. Mehmet Akif Ersoy University Journal of Education Faculty, 54, 184-199.

Söylemez, Y. (2018). 2018 Türkçe dersi öğretim programındaki kazanımların üst düzey düşünme becerileri açısından değerlendirilmesi. Journal of Turkish Research Institute, 63, 345-384. 
Süğümlü, Ü., Mutlu, H. H., \& Çinpolat, E. (2019). Ortaokul Türkçe dersi öğretmen kılavuz kitaplarının kullanılması ve kullanılmamasına ilişkin bir durum çalışması. Abant İzet Baysal University Journal of Faculty of Education, 19(4), 1667-1681.

Swartz, R. J., \& Perkins, D. N. (2016). Teaching thinking: Issues and approaches. New York: Routledge.

Şengül, M. (2005). İlköğretim 8. Sınıf Türkçe ders kitaplarındaki metinlere dayalı olarak hazırlanan sorular üzerine bir inceleme [Unpublished Master Thesis]. Firat University, Institute of Social Sciences, Elazı̆̆.

Temizkan, M. (2014). Ortaokul Türkçe ders kitaplarının Türkçe dersi öğretim programındaki temel beceriler açısından incelenmesi. Journal of Mother Tongue Education, 2(1), 49-72.

Tosunoğlu, M., \& Demir, E. (2014). MEB Yayınları 5. Sınıf Türkçe dersi öğrenci çalışma kitabındaki etkinliklerin dil öğrenme alanlarına ve taksonomiye göre değerlendirilmesi. Millî Ĕgitim Dergisi, 44(203), 74-83.

Uçgun, D. (2018). 1-5. sınıf Türkçe ve Türk kültürü çalışma kitaplarındaki Türkçe dersi etkinliklerinin programdaki kazanımlara göre değerlendirilmesi. International Journal of Turkish Literature Culture Education (TLCE), 7(2), 1148-1160.

Ulum, H., \& Taşkaya, S. M. (2019). Evaluation of the activities in the Turkish coursebooks (student's books and workbooks) used at the 2nd, 3rd, and 4th classes of state primary schools according to revised Bloom's taxonomy. Kastamonu Education Journal, 27(1), 107-118.

Yağmur, K. (2009). Türkçe ders kitapları dil gelişimini ne oranda desteklemektedir. Cito Education: Theory and Practice, 2, 53-64.

Wang, S., \& Wang, H. (2011). Teaching higher order thinking in the introductory MIS course: A model-directed approach. Journal of Education for Business, 86(4), 208213. 